\title{
Characterization and Optical and Dielectric Properties of Polyvinyl Chloride/Silica Nanocomposites Films
}

\author{
T. Abdel-Baset, M. Elzayat, and S. Mahrous \\ Physics Department, Fayoum University, Fayoum 63514, Egypt \\ Correspondence should be addressed to M. Elzayat; myfelzayat@yahoo.com
}

Received 20 January 2016; Revised 19 April 2016; Accepted 11 May 2016

Academic Editor: Yulin Deng

Copyright ( 2016 T. Abdel-Baset et al. This is an open access article distributed under the Creative Commons Attribution License, which permits unrestricted use, distribution, and reproduction in any medium, provided the original work is properly cited.

\begin{abstract}
Silica nanoparticles were synthesized by a sol-gel method and mixed with different amounts of polyvinyl chloride (PVC) to get nanocomposite films. The samples were characterized by XRD, HR-TEM, SEM, and FTIR. High resolution transmission electron microscopy (HR-TEM) proved that the average particle size of the nanosilica is $15 \mathrm{~nm}$. The scanning electron microscopy (SEM) showed that the nanosilica was well dispersed on the surface of the PVC films. Fourier Transform Infrared (FTIR) spectra for nanocomposite films intimate a significant change in the intensity of the characteristic peaks of the functional group with addition of nanosilica. The optical band gap was found to decrease with the addition of nanosilica while the refractive index increased. The dielectric constant $\varepsilon^{\prime}$, the dielectric loss modulus $M^{\prime \prime}$, and AC conductivity $\left(\sigma_{\mathrm{AC}}\right)$ were also studied. It was found that $\varepsilon^{\prime}$ increases with temperature for all samples, clear dielectric $\alpha$-relaxation observed from dielectric loss $M^{\prime \prime}$ around the glass temperature $\left(T_{g}\right)$, and this could be related to micro-Brownian motion of the main PVC chain. The activation energy was calculated, and the AC conductivity could be a hopping one. The results of this work are discussed and compared with previously obtained data.
\end{abstract}

\section{Introduction}

Polymer nanocomposite, particularly polyvinyl chloride (PVC) based material, attracted worldwide attention due to its industrial applications and academic interests [1-3]. In fact, there are many reports on different PVC based nanocomposites [4-10].

Silica nanoparticles are extensively studied for many applications such as photonic crystals [11, 12], chemical sensors [13], biosensors [14], nanofillers for advanced composite materials [15-17], markers for bioimaging [18], substrate for quantum dots $[19,20]$, and catalysts $[21,22]$. However many interesting reports indicated the uses of silica in the formation of modern polymer composites, such as poly(butylene terephthalate) (PBT) [23], poly(methyl acrylate) (PMA) [24], polyethylene (PE) [25], polypropylene (PP) [26], polystyrene (PS) [27], polyhydroxyethylmethacrylate (PHEMA) [28], polyurethane (PUR) [29], natural rubber [30], and acrylonitrile-butadiene elastomer (NBR) [31]. Motivation for the use of silica as a polymer filler comes primarily from its high thermal stability and the favorable strength properties of the resulting composites.
The mechanical properties and process ability of PVC filled with nano- $\mathrm{SiO}_{2}$ particles are widely investigated [32, 33]. It is noteworthy that the incorporation of nanosized silica into PVC-polymer gives rise to new types of nanocomposite polymer electrolytes. Generally, extensive research is still under processing on the mechanical and process ability properties of PVC composites filled with inorganic nanoparticles and on the dispersion of inorganic particles in polymeric matrix. However, there is a notable dearth of information with respect to the optical and dielectric properties of this composite.

It seems that much more investigations of quantitative characterization of its effective interfacial interactions are required. So, it seems essential to investigate both optical properties and interfacial interactions of PVC composites filled with inorganic nanoparticles. The most important parameter governing the utilization of silica nanoparticles in the research work is the optical properties. The transparency and refractive index are important optical properties of polymer nanocomposite. From all the above we investigated the effect of the addition nanosilica to PVC matrix into the optical and dielectric properties of the nanocomposite films. 


\section{Experimental Work}

\subsection{Materials and Methods}

2.1.1. Synthesis of $\mathrm{SiO}_{2}$ Nanoparticles. Silica nanoparticles were synthesized via a sol-gel method. A desired amount of sodium silicate solution $\left(\mathrm{Na}_{2} \mathrm{SiO}_{3}\right)$ with molecular weight of 122.06 (Sigma-Aldrich) was diluted with distilled water under stirring for $15 \mathrm{~min}$, and diluted hydrochloric acid was used to precipitate it. The precipitate was filtered and washed several times with distilled water until complete removal of sodium chloride. This precipitate was dried in air overnight.

2.1.2. Preparation of $\mathrm{PVC} / \mathrm{SiO}_{2}$ Nanocomposite. Different concentrations $\left(1,2\right.$, and 4 wt.\%) of the synthesized $\mathrm{SiO}_{2}$ nanoparticles were added to PVC (Polymer Laboratories, Essex, UK) according to the relation

$$
x(\text { wt. } \%)=\left(\frac{w_{f}}{w_{p}+w_{f}}\right) \times 100,
$$

where $w_{f}$ and $w_{p}$ represent the weights of $\mathrm{SiO}_{2}$ and PVC, respectively. We get the nanocomposite films through the following steps: $1 \mathrm{~g}$ of PVC was dissolved in $25 \mathrm{~mL}$ tetrahydrofuran (THF, Aldrich, Germany) with stirring until a transparent solution was watched. The calculated weight of the prepared $\mathrm{SiO}_{2}$ nanoparticles was added to the solution under ultrasonic stirrer at room temperature (RT) for $30 \mathrm{~min}$ to prevent the agglomeration of the nanoparticles. The different solutions of the mixtures were then casted in Petri dishes and kept for $24 \mathrm{~h}$ to dry in air at RT.

2.1.3. Characterization Techniques. X-ray diffraction (XRD) was used to characterize the sensitized $\mathrm{SiO}_{2}$ powder, the films of pure PVC, and the films of PVC loaded with $\mathrm{SiO}_{2}$ nanoparticles. Analysis of the samples was achieved using a Rigaku miniflex diffractometer with $\mathrm{CuK} \alpha$ radiation $(\lambda=$ $1.5406 \AA$ ). The particle size of the as-synthesized nanosilica was determined using high resolution transmission electron microscopy (HR-TEM; JEM 2100, JEOL, Japan). Scanning electron microscopy (SEM; Inspect S, FEI, Holland) images were taken for the nanocomposite films. The FTIR spectra were taken using a Shimadzu 8201 PC spectrophotometer in the range of $4000-400 \mathrm{~cm}^{-1}$. A Shimadzu UV-3600 UV-VIS-NIR spectrophotometer was used to study optical characterization in the wavelength range of $200-850 \mathrm{~nm}$. LCR meter (model 3532, HIOKI, Ueda, Nagano, Japan) was used to investigate the temperature dependence of the dielectric characterization. A T-type thermocouple was used to measure the temperature (with an accuracy of $\pm 1^{\circ} \mathrm{C}$ ).

\section{Results and Discussions}

3.1. X-Ray Diffraction. X-ray diffraction spectra of pure PVC, pure $\mathrm{SiO}_{2}$ nanoparticles, and $4 \mathrm{wt} \% \mathrm{PVC}^{-\mathrm{SiO}_{2}}$ nanocomposite films are shown in Figure 1. The amorphous nature of the nanosilica was clearly observable, consistent with previous reports $[34,35]$. Also, the amorphous nature of pure PVC is indicated through a broad peak in the region

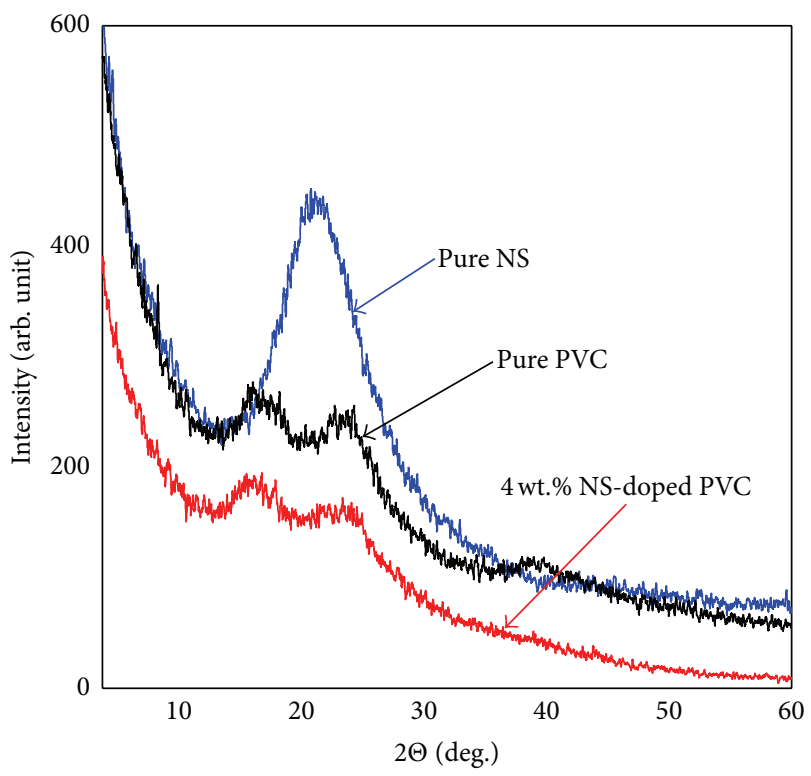

Figure 1: X-ray diffraction pattern for pure PVC, pure $\mathrm{SiO}_{2}$ nanoparticles, and $4 \mathrm{wt} \% \mathrm{SiO}_{2}$-doped PVC.

of $15-30^{\circ}$ [36]. Moreover the spectra for the composite intimate a wide and shallow peak, suggesting an amorphous structure of the nanocomposite. This shows that the addition of silica nanoparticles causes a decrease in the degree of crystallinity and a simultaneous increase in the amorphicity of the composite.

3.2. Characterization. The average size and shape of the asprepared $\mathrm{SiO}_{2}$ nanoparticles were tested through HR-TEM image. It can be seen from Figure 2(a) that the average particle size is about $15 \mathrm{~nm}$. Also, SEM was used to examine the morphology and dispersion of $\mathrm{SiO}_{2}$ nanoparticles on the surface of PVC films. Figures 2(b) and 2(c) show the SEM images of selected nanocomposite films, showing a good dispersion of $\mathrm{SiO}_{2}$ on the surface of the PVC films. This proves the validity of our synthesis process for obtaining nanosilica.

3.3. FTIR Spectroscopy. Figure 3 shows the FITR spectra for the nanocomposite films. The characteristic peaks of the saturated C-H groups on PVC chains appeared at 2970$2800 \mathrm{~cm}^{-1}, 1428 \mathrm{~cm}^{-1}$, and $1327 \mathrm{~cm}^{-1}$ absorption. For both the pure PVC and $\mathrm{PVC}-\mathrm{SiO}_{2}$ nanocomposite films, C-H band at $2953 \mathrm{~cm}^{-1}$ appeared. Unexpectedly, C-H band at $2907 \mathrm{~cm}^{-1}$ surpasses the band at $2953 \mathrm{~cm}^{-1}$, which might be due to the presence of isooctyle groups on the surface. The peaks at $695 \mathrm{~cm}^{-1}$ and $615 \mathrm{~cm}^{-1}$ are attributed to $\mathrm{C}-\mathrm{Cl}$ bond stretching [36]. The observed peak at $1250 \mathrm{~cm}^{-1}$ is attributed to the $\mathrm{C}-\mathrm{C}$ swing vibration in the group $\mathrm{CH}_{2}-\mathrm{CHCl}$. Also, at $945 \mathrm{~cm}^{-1}$ an absorption peak is seen which could be related to the $\mathrm{Si}-\mathrm{OH}$ group ( $\mathrm{Si}-\mathrm{O}-$ stretching). At about 797 and $1095 \mathrm{~cm}^{-1}$, the absorption peaks are initiated by $\mathrm{Si}-\mathrm{O}-\mathrm{Si}$ symmetric and asymmetric stretching vibration, respectively, demonstrating the generation of $\mathrm{Si}-\mathrm{O}-\mathrm{Si}$ in the system [37]. 

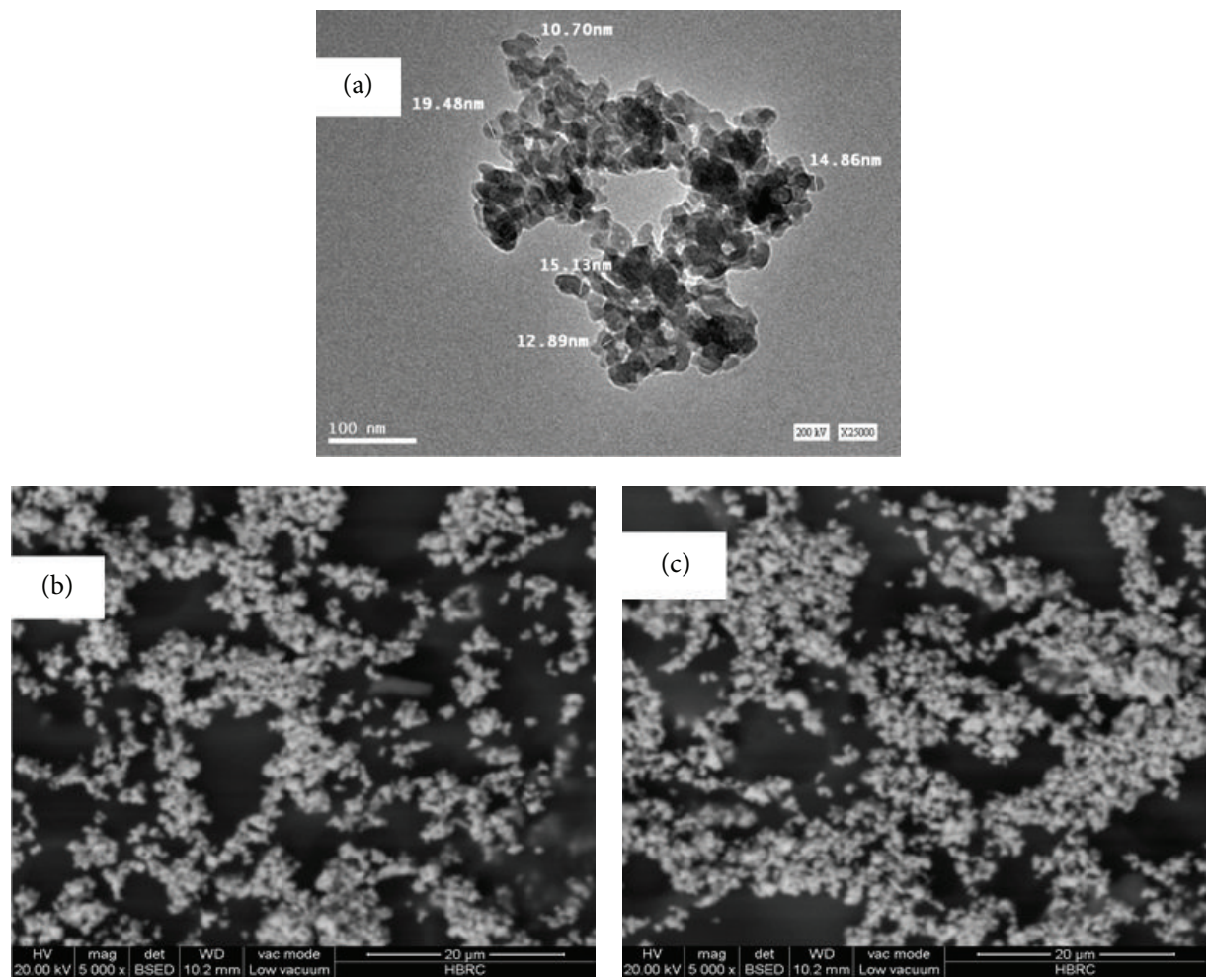

Figure 2: (a) HR-TEM of $\mathrm{SiO}_{2}$ nanoparticles and SEM images for (b) $1 \mathrm{wt} \% \mathrm{SiO}_{2}$-doped PVC and (c) 4 wt $\% \mathrm{SiO}_{2}$-doped PVC.

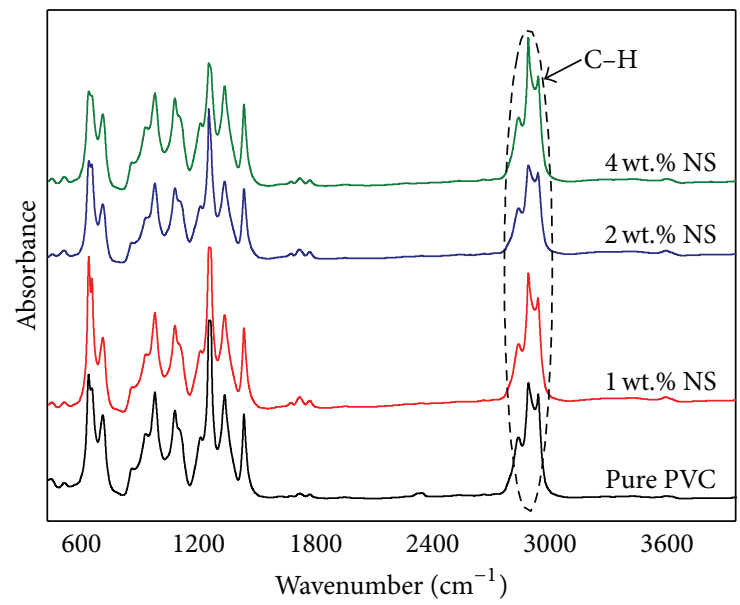

FIGURE 3: FTIR spectra for the $\mathrm{PVC}-\mathrm{SiO}_{2}$ nanocomposite films.

Usually, the long-range coupling Coulomb interactions cause the splitting of the peak of the $\mathrm{Si}-\mathrm{O}-\mathrm{Si}$ asymmetric stretching vibration into two components: a transverse optical (TO) and a longitudinal optical (LO) component. The peak close to $1095 \mathrm{~cm}^{-1}$ has been generally caused by the TO component, whereas the shoulder at $1186 \mathrm{~cm}^{-1}$ under the peak of $1095 \mathrm{~cm}^{-1}$ is denoted as the $\mathrm{LO}$ component [38]. The absorption peak at about $1000-1430 \mathrm{~cm}^{-1}$ is related to the overlap of Si-O-Si $\left(1000-1100 \mathrm{~cm}^{-1}\right)$, Si-O-C $\left(1080-1120 \mathrm{~cm}^{-1}\right)$, and $\mathrm{C}-\mathrm{O}-\mathrm{C}\left(1000-1300 \mathrm{~cm}^{-1}\right)$. The observed FTIR data are in good agreement with the results of [39].
Also, as is seen in Figure 3, the FTIR bands of PVC$\mathrm{SiO}_{2}$ nanocomposite films intimate a regular increase in the intensity of the absorption peaks with $\mathrm{SiO}_{2}$ particle loading. This was related to the formation of bonds between the constituents of the composite materials.

\subsection{Optical Properties}

3.4.1. Optical Band Gap and Urbach Energies for and PVC$\mathrm{SiO}_{2}$ Nanocomposite Films. The optical behavior of materials is described by optical constants. Figure 4(a) shows the absorbance spectra of pure PVC and $\mathrm{PVC}-\mathrm{SiO}_{2}$ nanocomposite films. It is obvious that the absorbance increases with increasing $\mathrm{SiO}_{2}$ nanoparticles ratio in $\mathrm{PVC}-\mathrm{SiO}_{2}$ nanocomposite. As is known, $\mathrm{PVC}$ is transparent in the visible region. This is clearly shown in Figure 4(b), while the transmittance decreases in the PVC-SiO ${ }_{2}$ nanocomposite sample. It is known that sol-gel method causes many lattice defects in the silica, resulting in a decrease in the transparency of the nanocomposite with increasing nano- $\mathrm{SiO}_{2}$ content. The formula ( $\alpha=$ absorbance/films thickness) was used to calculate the dependence of the absorption coefficient $(\alpha)$ on frequency. The optical band gap $\left(E_{g}\right)$ is determined by Tauc's relation [40, 41]:

$$
\alpha h v=B\left(h v-E_{g}\right)^{m},
$$

where $h \nu$ is the incident photon energy, $B$ is the probability parameter for transition, and $m$ adopts being $1 / 2$ and 2 for allowed direct and allowed indirect transitions [42], 


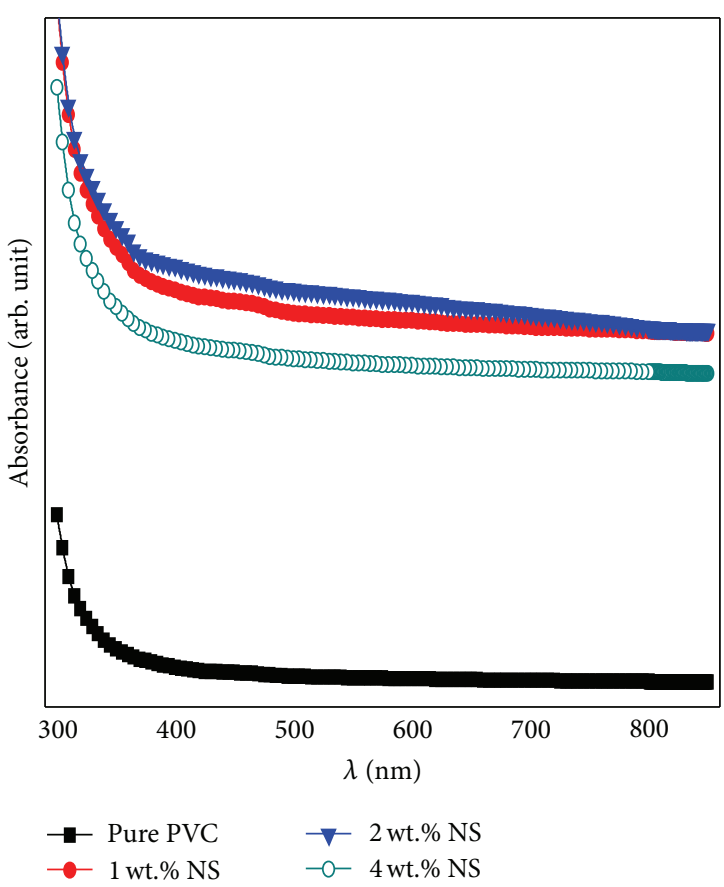

(a)

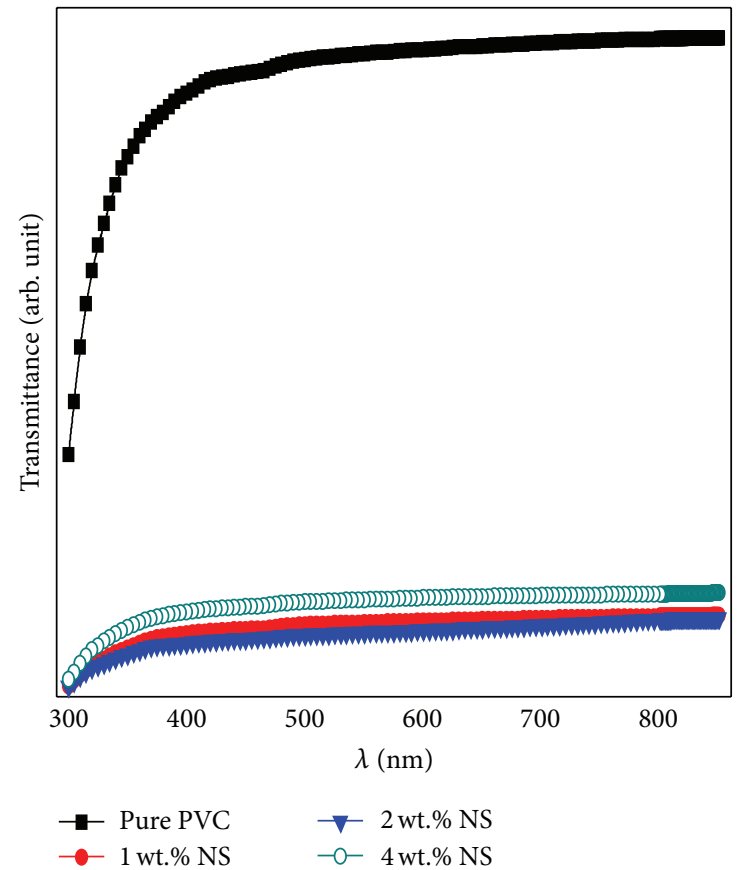

(b)

FIgUre 4: (a) The absorbance spectra for pure PVC and PVC-SiO ${ }_{2}$ nanocomposite films. (b) The transmittances spectra for pure PVC and PVC-SiO ${ }_{2}$ nanocomposite films.

TABLE 1: The direct energy band gap, $E_{g}$, Urbach energy, $E_{U}$, and various optical dispersion parameters for pure $\mathrm{PVC}$ and $\mathrm{PVC} / \mathrm{SiO}_{2}$ nanocomposite films.

\begin{tabular}{lcccc}
\hline Samples & $E_{g}(\mathrm{eV})$ & $E_{U}(\mathrm{eV})$ & $E_{0}(\mathrm{eV})$ & $E_{d}(\mathrm{eV})$ \\
\hline Pure (PVC) & 3.93 & 0.37 & 6.6 & 8.6 \\
$1 \% \mathrm{SiO}_{2}$ & 3.81 & 0.85 & 6.8 & 187.1 \\
$2 \% \mathrm{SiO}_{2}$ & 3.76 & 0.85 & 6.8 & 199 \\
$4 \% \mathrm{SiO}_{2}$ & 3.87 & 0.82 & 6.4 & 138.4 \\
\hline
\end{tabular}

respectively. The direct band gaps were obtained from the plots of $(\alpha h \nu)^{2}$ versus $h v$ at RT as shown in Figure 5, and the $E_{g}$ values were estimated by extrapolating the linear part of $(\alpha h \nu)^{2}$ to zero. The obtained $E_{g}$ values are given in Table 1. It was found that the $E_{g}$ values decrease with the addition of nanosilica which indicates that the position of the electronic band gap of the nanocomposite depends on the concentration of $\mathrm{SiO}_{2}$ on it.

The absorption coefficient near the fundamental absorption edge is exponentially dependent on $h v$ and obeys the empirical Urbach relation. The Urbach energy $\left(E_{U}\right)$, which is the width of the tails states in the band gap associated with the structural defects and disorder within the polymer matrix, can be calculated by the relation [43]

$$
\alpha(h v)=\alpha_{o} \exp \left(\frac{h v-E_{1}}{E_{U}}\right), \quad h v<E_{g}
$$

where $\alpha(h \nu)$ is the absorption coefficient as a function of the photon energy $(E)$ and $\alpha_{o}$ and $E_{1}$ are constants determined from $\ln (\alpha)$ versus $h v$ plot (Figure 6). $E_{1}$ approximately coincides with the energy of the lowest free exciton state at zero temperature. The value of $E_{U}$ was obtained from the inverse of the slope of $\ln \alpha$ versus $h v$, and the obtained values are listed in Table 1 . The $E_{U}$ values change inversely with optical band gap. The increase of $E_{U}$ suggests that the atomic structural disorder of PVC increases by nanosilica doping; this increase would lead to a redistribution of states, from band to tail, thus allowing for a greater number of possible bands-to-tail and tail-to-tail transitions [44]. $E_{U}$ is often interpreted as the width of the tail of localized states in the gap region associated with the tailing of the valance band density of states and is broader than the conduction band tail.

3.4.2. Refractive Index Dispersion of Pure $\mathrm{PVC}$ and $\mathrm{PVC} / \mathrm{SiO}_{2}$ Nanocomposite Films. The refractive index $(n)$ could be calculated using the reflectance $(R)$ and the extinction coefficient, $k$, (where $k=\alpha \lambda / 4 \pi$ ) of films as follows [44]:

$$
n=\left(\frac{1+R}{1-R}\right)+\sqrt{\frac{4 R}{(1-R)^{2}}-k^{2}},
$$

where $R=1-\sqrt{(T * \exp (A))}$ is the reflectance calculated from the absorbance $(A)$ and transmission $(T)$ spectra [44].

Figure 7 shows the refractive index distributions of pure $\mathrm{PVC}$ and $\mathrm{PVC}-\mathrm{SiO}_{2}$ nanocomposite films. The refractive index are found to increase with the addition of $\mathrm{SiO}_{2}$ nanoparticles. Such increase in $n$ may extend the usability of these materials as antireflection coating.

We used the Wemple-DiDomenico model describes that the dielectric response for transitions below the optical gap 


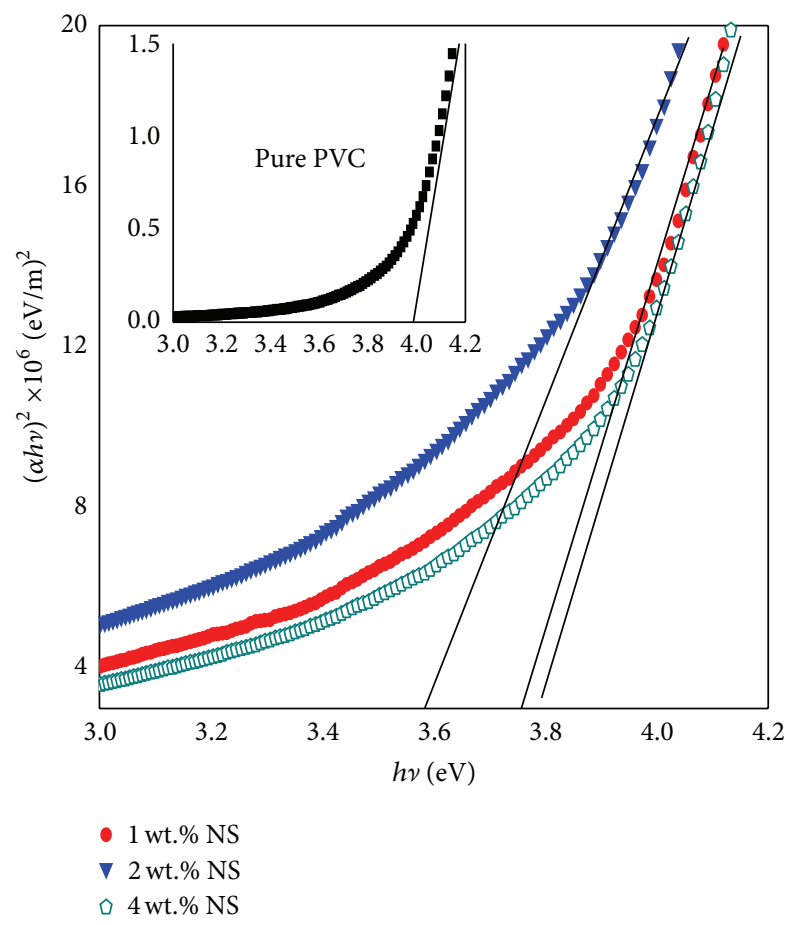

FIgURE 5: Plot of $(\alpha h \nu)^{2}$ versus $h \nu$ for pure PVC and $\mathrm{PVC}-\mathrm{SiO}_{2}$ nanocomposite films.

was used to calculate the single-oscillator parameters. The dispersion data of the refractive index can be described by a single-oscillator model, where $E_{0}$ and $E_{d}$ are single-oscillator constants [45]:

$$
n^{2}-1=\frac{E_{0} E_{d}}{E_{0}^{2}-E^{2}}
$$

$E_{0}$ is the single-oscillator energy and $E_{d}$ is the dispersion energy which measures the average strength of interband optical transition, $E_{0}$ and $E_{d}$ values can be determined as the slope and the intercept of Figure 8, according to (5), and the obtained values are listed in Table 1 . It is found that $E_{0} \approx 2 E_{g}$; this result agrees with the single-oscillator model [45].

\subsection{Dielectric Properties}

3.5.1. Dielectric Permittivity. The dielectric behavior of polymer nanocomposite materials is a powerful technique for studying the relaxation and conduction mechanisms in polymeric materials [46].

Figure 9 displays the temperature dependence of $\varepsilon^{\prime}$ at selected frequencies for pure PVC and $\mathrm{PVC}-\mathrm{SiO}_{2}$ nanocomposite films. It is shown that $\varepsilon^{\prime}$ varies slowly with increasing the temperature up to $T_{g}$ and then increases with further increase in temperature till reaching a saturation region and then it decreases again. The relaxation process observed near the glass transition temperature for the prepared nanocomposite ( $\alpha$-relaxation) is attributed to the cooperative dipolar orientations. This relaxation process corresponds to the segmental relaxation associated with the glass transition at

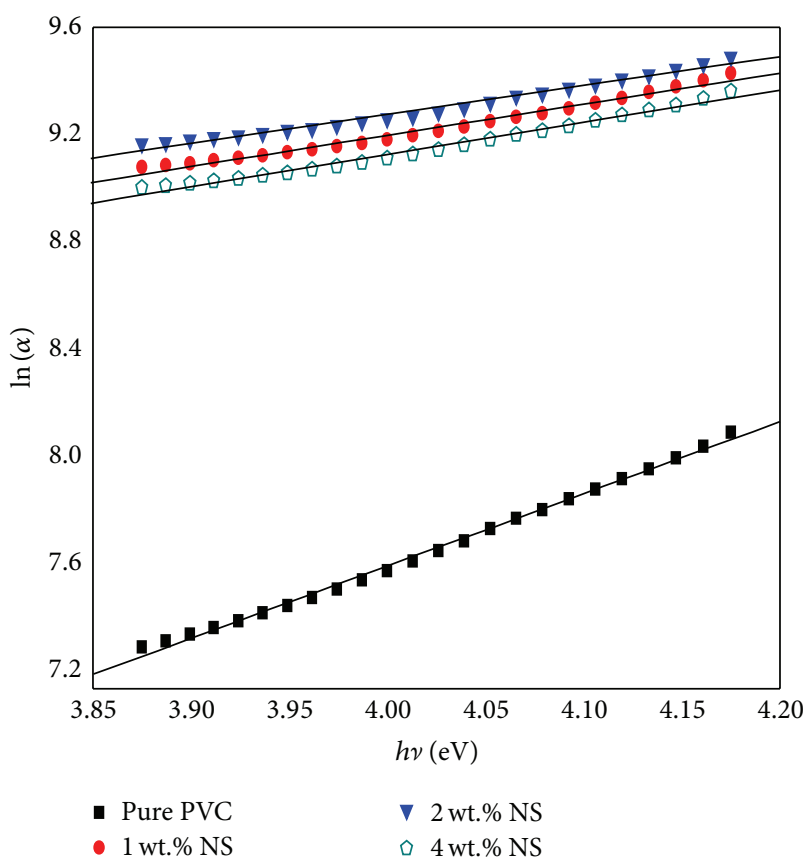

Figure 6: Plots of $\ln (\alpha)$ versus $h v$ for pure PVC and PVC-SiO nanocomposite films.

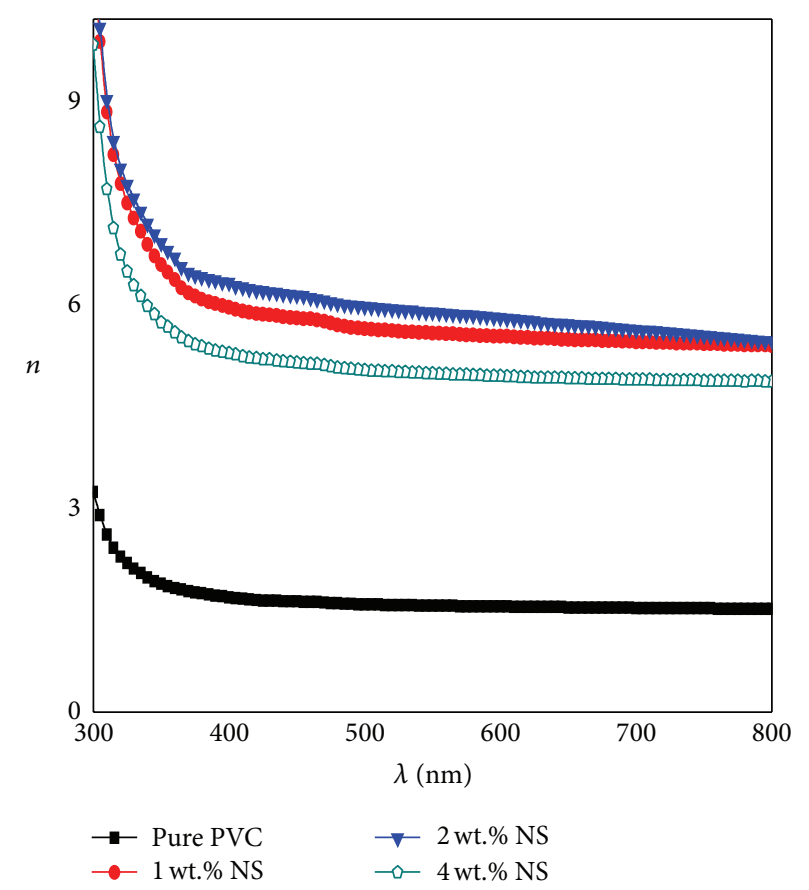

FIGURE 7: The refractive index $(n)$ curve for pure PVC and PVC-SiO nanocomposite films.

which the micro-Brownian motion of long chain segments in the amorphous regions of PVC [47].

At lower temperatures, the thermal energy that is absorbed by the polymeric material, at a certain fixed frequency, is small and a small number of dipoles can rotate with 


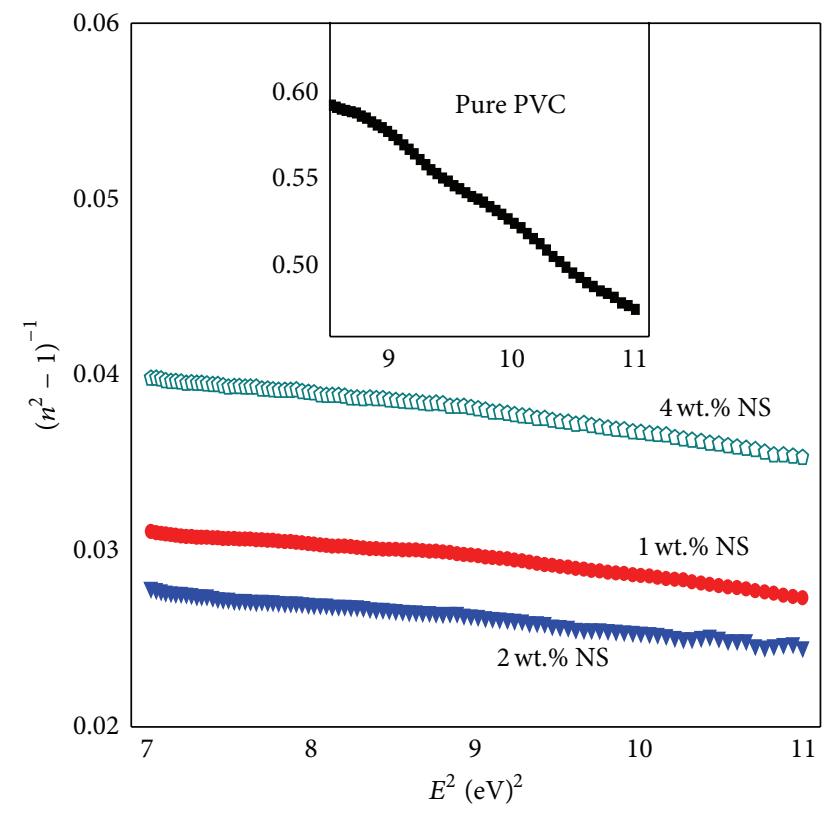

FIgUre 8: Plots of $\left(n^{2}-1\right)^{-1}$ against $(E)^{2}$ for pure PVC and $\mathrm{PVC}-\mathrm{SiO}_{2}$ nanocomposite films.

small angles. With increasing temperatures, $\varepsilon^{\prime}$ value is determined by the number of orienting dipoles per unit volume and their dipole moments [46]. As the temperature increased, the viscosity of polymeric films is decreased and the dipoles gain sufficient energy and can orient themselves easily in the direction of the applied electric field; thus $\varepsilon^{\prime}$ increase with increasing temperatures. Also, the chain segments get sufficient thermal energy to speed up its rotational motion and consequently polarization increases [48]. However, the specific volume of the polymer increases with the further increase in temperature, and hence $\varepsilon^{\prime}$ value is increased at higher temperatures $[49,50]$.

It is also clear that $\varepsilon^{\prime}$ decreases with the increase of frequencies for all samples. The decreases may be attributed to the decreasing of the number of dipoles, which contribute to polarization, or dipole structure is no longer able to respond to the applied electric field; this leads to reduction in the $\varepsilon^{\prime}$ value.

Moreover, $\varepsilon^{\prime}$ seems to decrease to lower values after adding the nanosilica to PVC matrix. Silica nanoparticles have more surface area whose effect combined with the resulting change in PVC morphology and the space charge distribution leads to reduction in the internal field. This reduction could be the cause of the $\varepsilon^{\prime}$ reduction for pure PVC and $\mathrm{PVC}-\mathrm{SiO}_{2}$ nanocomposite films.

3.5.2. Electric Modulus. At low frequencies and high temperatures the observed values of dielectric permittivity do not refer to the bulk of the material; this is related to the so-called "interfacial polarization" dominant in these composites polymeric materials [51]. To avoid contributing of the interfacial polarization, the modulus formalism can be used for analyses of the dielectric behavior of PVC.
In addition, the recorded dielectric data can be expressed in terms of the complex electric modulus $\left(M^{*}\right)$ [52], which is defined as the inverse of the complex permittivity $\left(\varepsilon^{*}\right)$ :

$$
\begin{aligned}
& M^{*}=M^{\prime}+i M^{\prime \prime} \\
& M^{*}=\frac{1}{\varepsilon^{*}}=\frac{\varepsilon^{\prime}}{\varepsilon^{\prime 2}+\varepsilon^{\prime \prime 2}}+i \frac{\varepsilon^{\prime \prime}}{\varepsilon^{\prime 2}+\varepsilon^{\prime \prime 2}},
\end{aligned}
$$

where $M^{\prime}$ and $M^{\prime \prime}$ are the real and imaginary parts of the dielectric modulus, respectively. Figures 10(a)-10(d) show the temperature dependence of $M^{\prime}$ for PVC and PVC-SiO nanocomposite films at different frequencies; it is observed that the values of $M^{\prime}$ decrease with increasing temperatures for pure $\mathrm{PVC}$ and $\mathrm{PVC}-\mathrm{SiO}_{2}$ nanocomposite films; at high temperatures $M^{\prime}$ tends to reach a constant value indicating the removal of the electrode polarization for the investigated samples owing to thermally activated nature of dielectric constant [52].

The temperature-dependent behavior of $M^{\prime \prime}$ for pure $\mathrm{PVC}$ and $\mathrm{PVC}-\mathrm{SiO}_{2}$ nanocomposite films at different frequencies is displayed in Figure 11. The $M^{\prime \prime}$ spectrum shows asymmetric peak corresponding to $\alpha$-relaxation process which is related to the micro-Brownian motion in the amorphous region of the main polymer chain [47]. The $M^{\prime \prime}$ peaks shift to higher temperatures with increasing frequency because the increase of temperature releases more dipoles; hence the density of dipoles contributing the relaxation process increases with increasing temperature. The region to the left of $M^{\prime \prime}$ peak is where the dipoles rotate faster, and the region to the right is where the dipoles are spatially confined to their equilibrium positions.

3.5.3. The AC Conductivity. To investigate the influence of adding the silica nanoparticles on the AC conductivity $\left(\sigma_{\mathrm{AC}}\right)$ for pure PVC and PVC-SiO${ }_{2}$ nanocomposite films, the $\sigma_{\mathrm{AC}}$ values were calculated using the relation $\left(\sigma_{\mathrm{AC}}=\omega \varepsilon_{0} \varepsilon^{\prime \prime}\right)$, where $\omega$ is the angular frequency, $\varepsilon_{o}$ is the permittivity of the free space, and $\varepsilon^{\prime \prime}$ represents the dielectric loss. The activation energy $\left(E_{a}\right)$ for all samples was calculated according to the Arrhenius relation [53]: $\sigma_{\mathrm{AC}}=\sigma_{o} \exp \left(-E_{a} / k T\right)$. Figures $12(\mathrm{a})-12(\mathrm{~d})$ represent the measured ac conductivity $\left(\ln \sigma_{\mathrm{AC}}\right)$ as a function of the reciprocal of temperature $(1000 / T)$ for pure $\mathrm{PVC}$ and $\mathrm{PVC}-\mathrm{SiO}_{2}$ nanocomposite films. It is clear that $\sigma_{\mathrm{AC}}$ for each sample increases with increasing the applied frequency. This may be due to the increase of the absorbed energy which leads to increase of the number of the charge carriers that contribute to the conduction process. These observations agreed with the published data for different polymers and amorphous nanoparticles [53-55].

The values of $E_{a}$ for all investigated samples at $f=$ $60 \mathrm{kHz}$ to $2 \mathrm{MHz}$ and their corresponding temperature range $(300 \mathrm{~K} \leq T \leq 370 \mathrm{~K})$ are summarized in Table 2 . We show that the values of $E_{a}$ for PVC are decreased with increasing the content of silica nanoparticles; moreover the increase of $\sigma_{\mathrm{AC}}$ with temperature may have been caused by an increase in the absorbed energy, which leads to an increase in the number of charge carriers that contribute to the conduction process. This reveals that the conduction mechanism could 


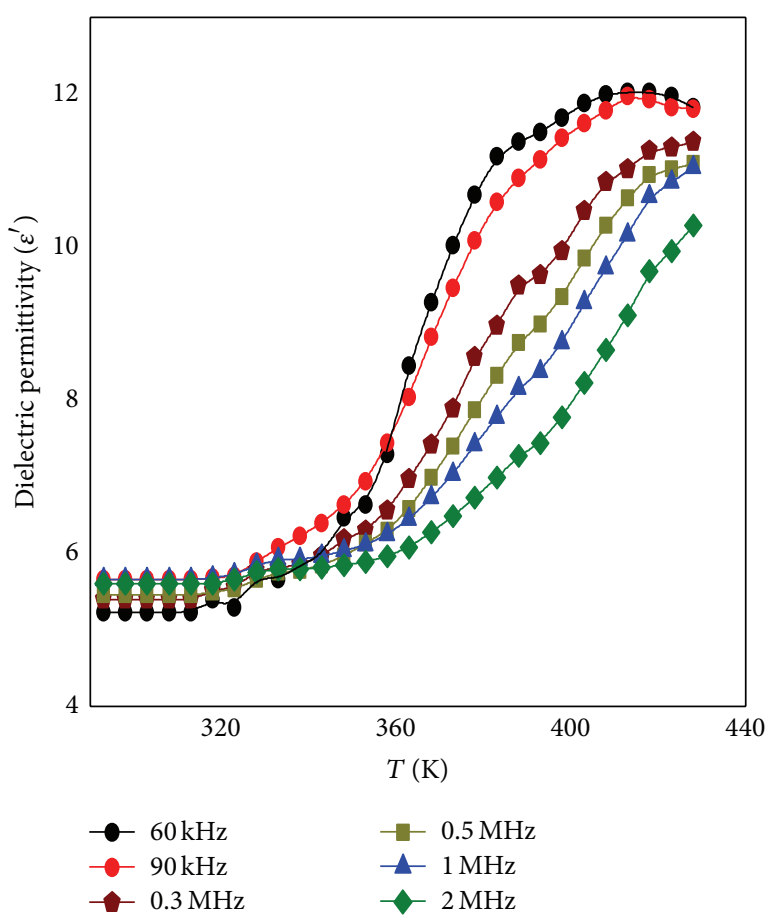

(a) Pure PVC

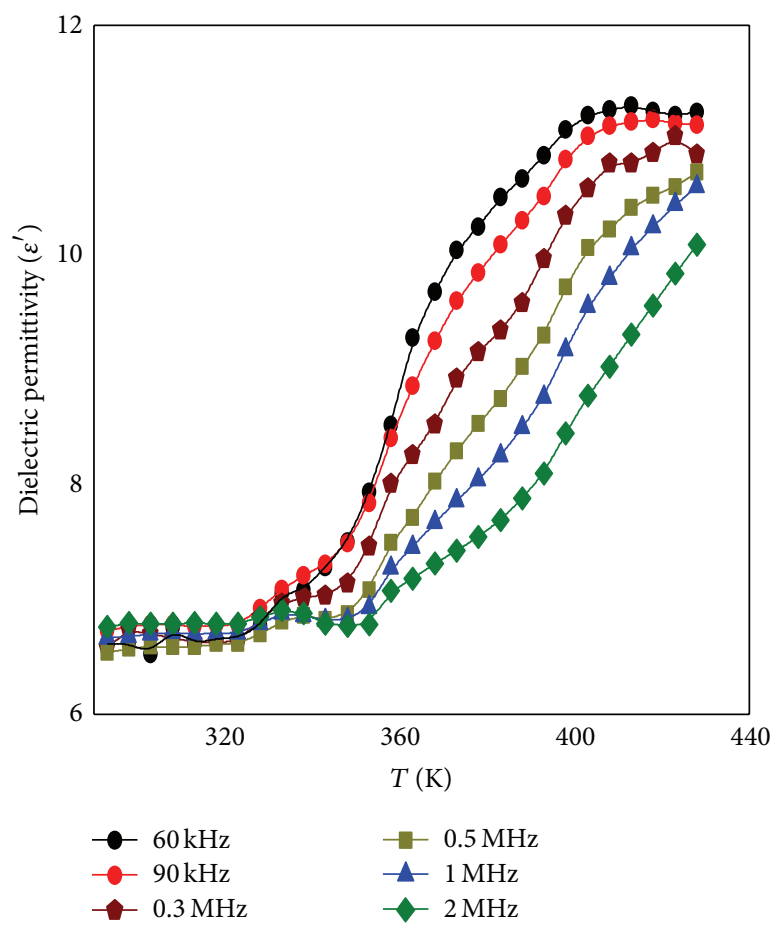

(c) 2 wt.\% NS

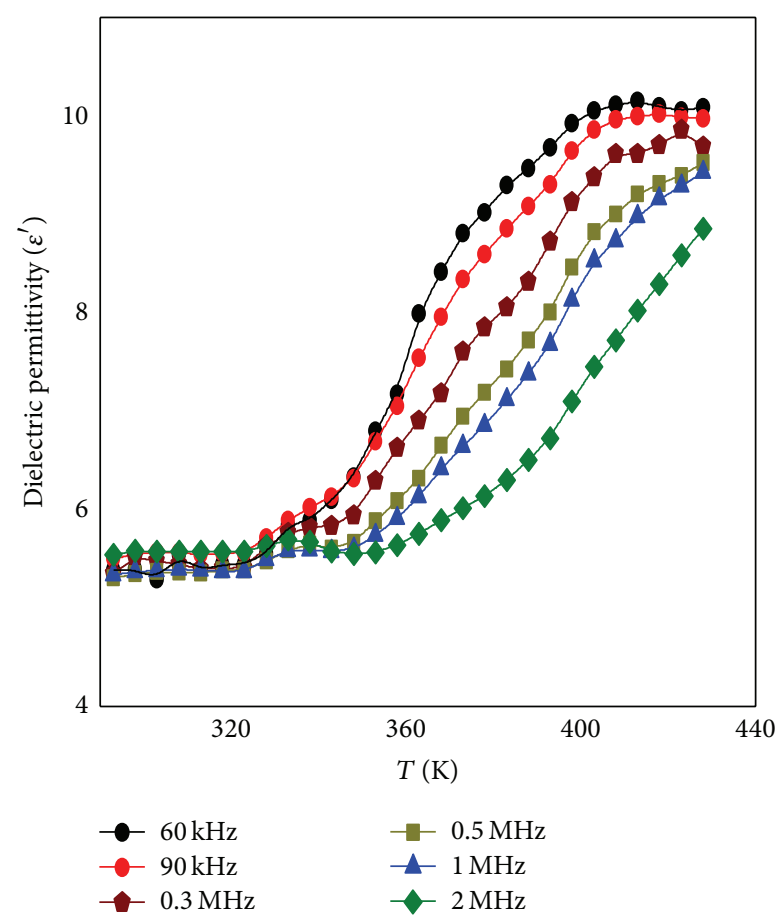

(b) $1 \mathrm{wt} . \% \mathrm{NS}$

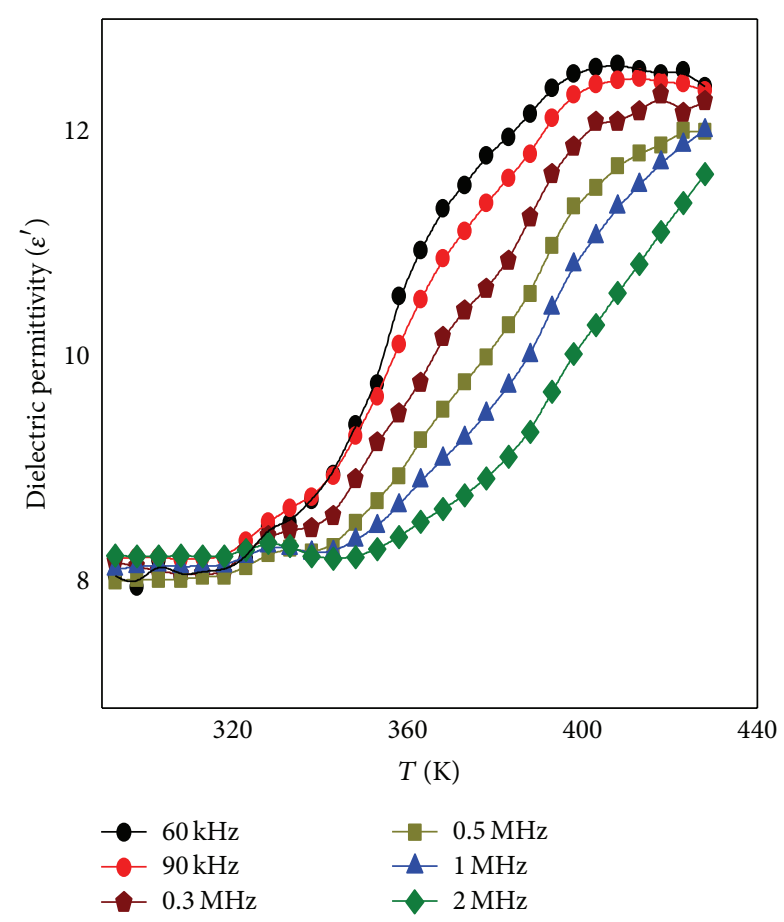

(d) 4 wt.\% NS

FIGURE 9: The variation of dielectric constant $\varepsilon^{\prime}$ as a function of temperature for pure $\mathrm{PVC}$ and $\mathrm{PVC}-\mathrm{SiO}_{2}$ nanocomposite films with different concentrations at different frequencies. 


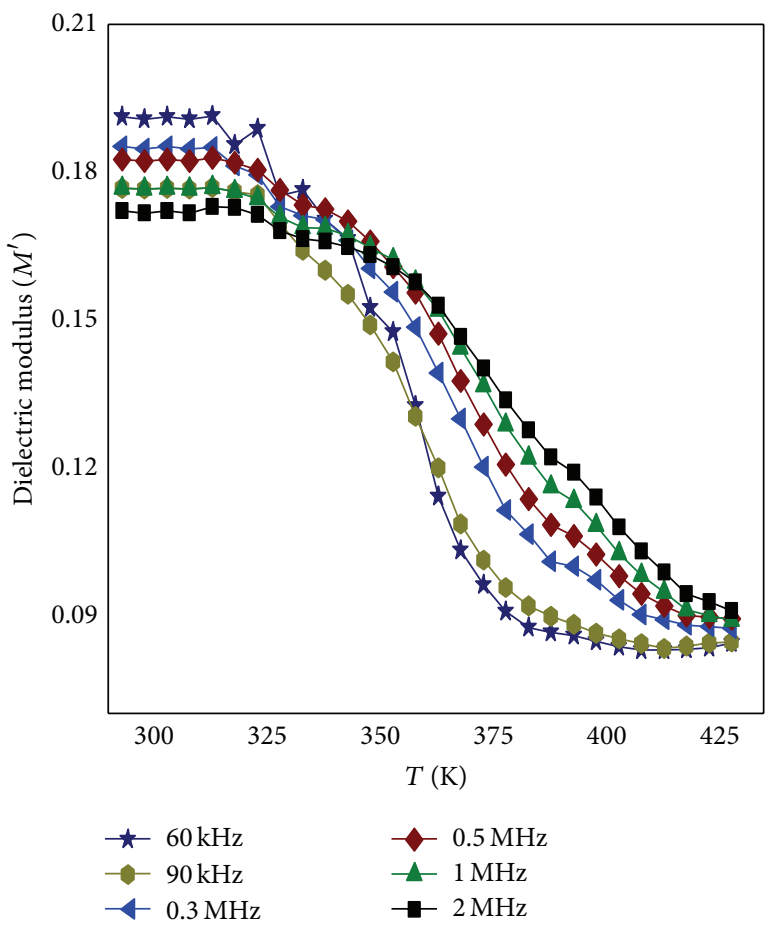

(a) Pure PVC

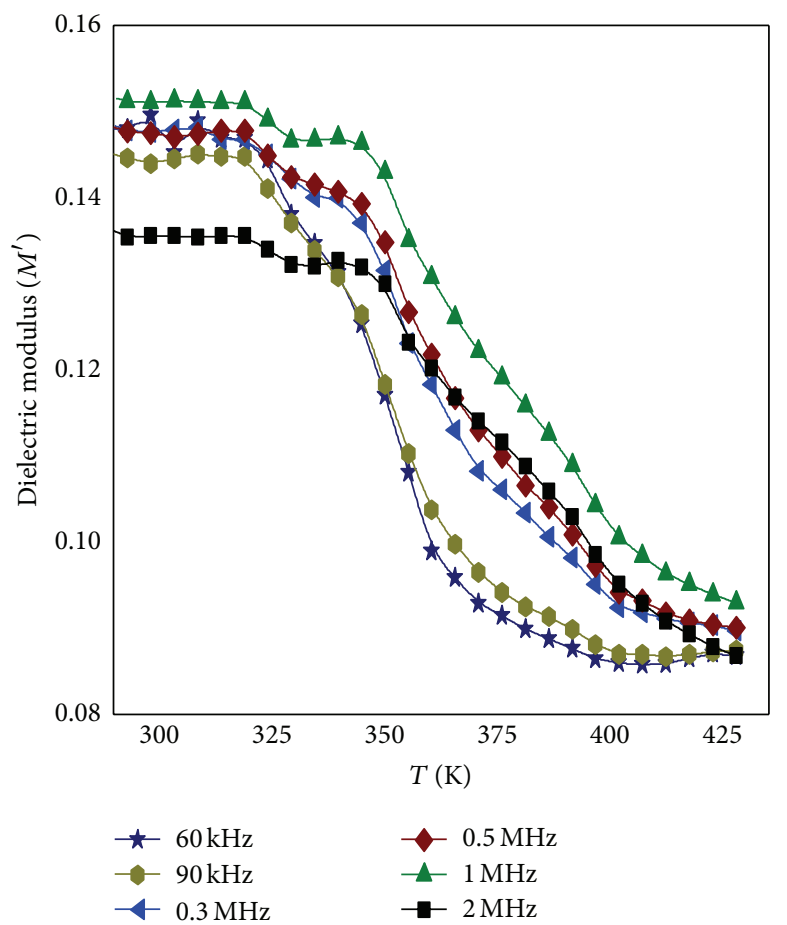

(c) 2 wt. $\% \mathrm{NS}$

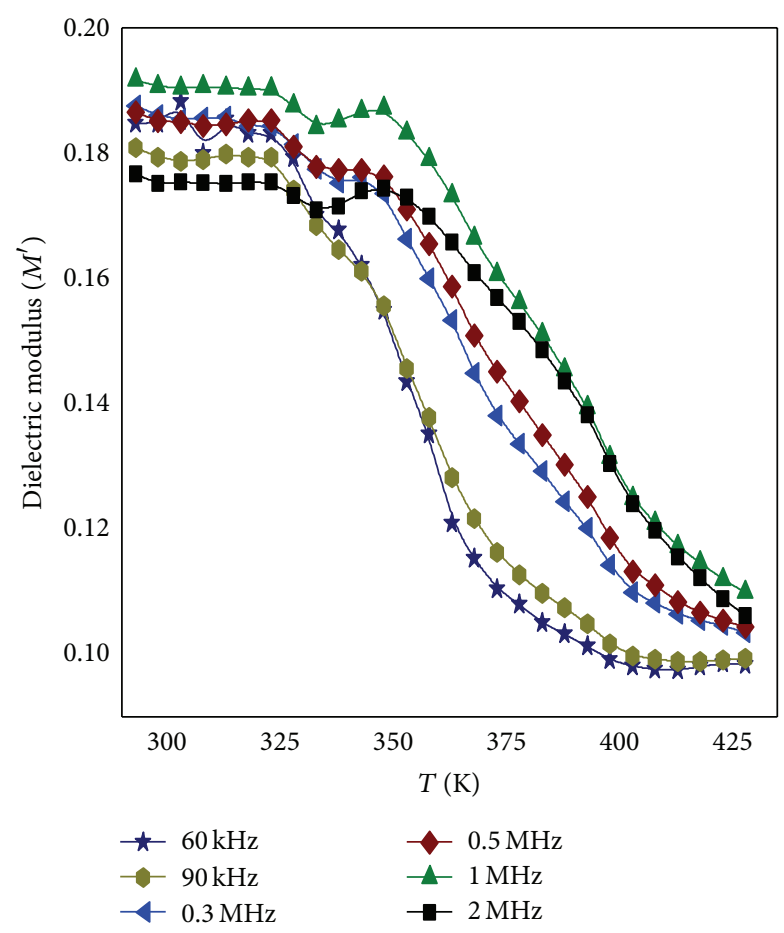

(b) $1 \mathrm{wt} . \% \mathrm{NS}$

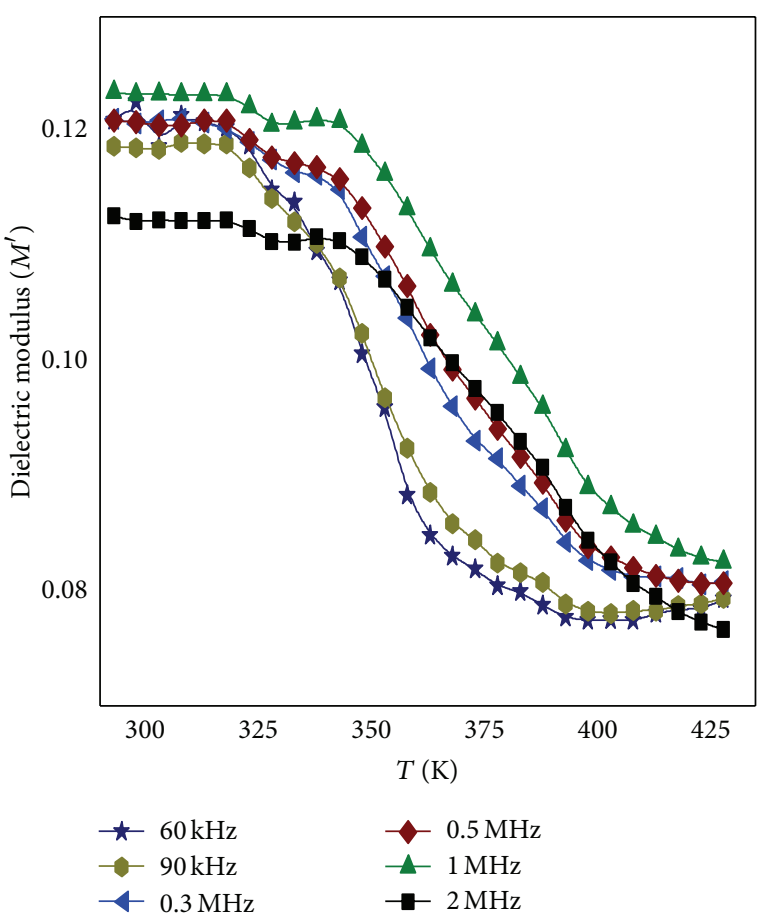

(d) 4 wt.\% NS

FIgure 10: The variation of dielectric modulus $M^{\prime}$ as a function of temperature at some fixed frequencies for pure $\mathrm{PVC}_{\text {and }} \mathrm{PVC}-\mathrm{SiO}_{2}$ nanocomposite films. 


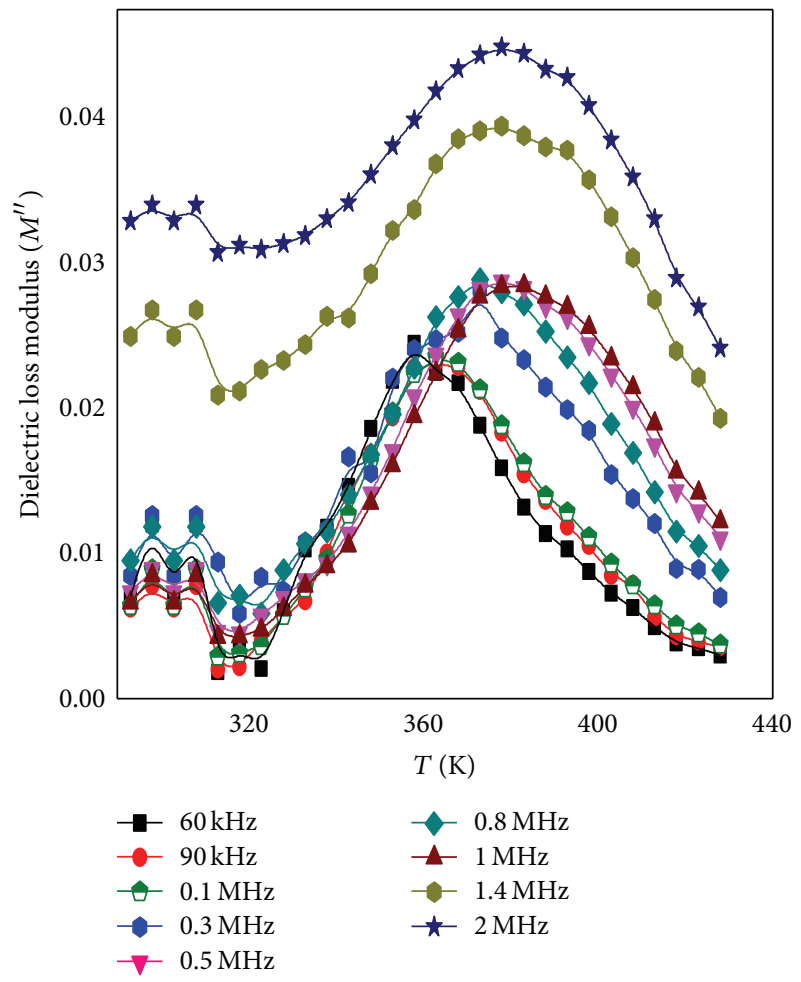

(a) Pure PVC

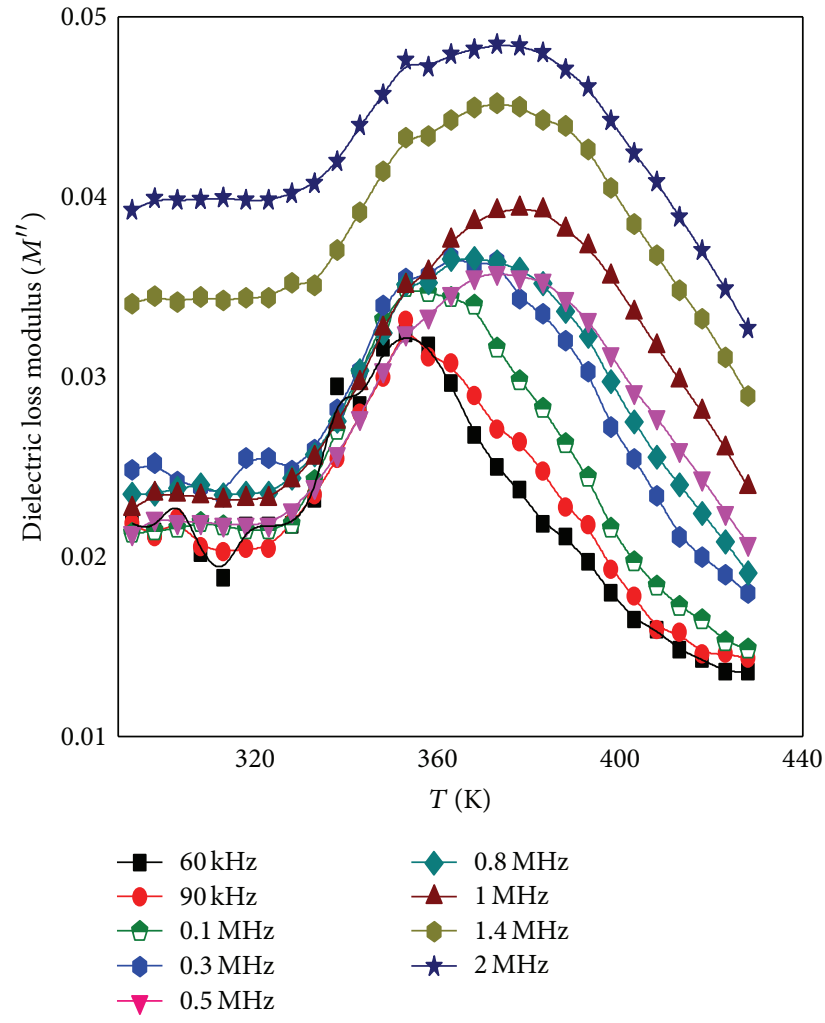

(c) $2 \mathrm{wt} . \% \mathrm{NS}$

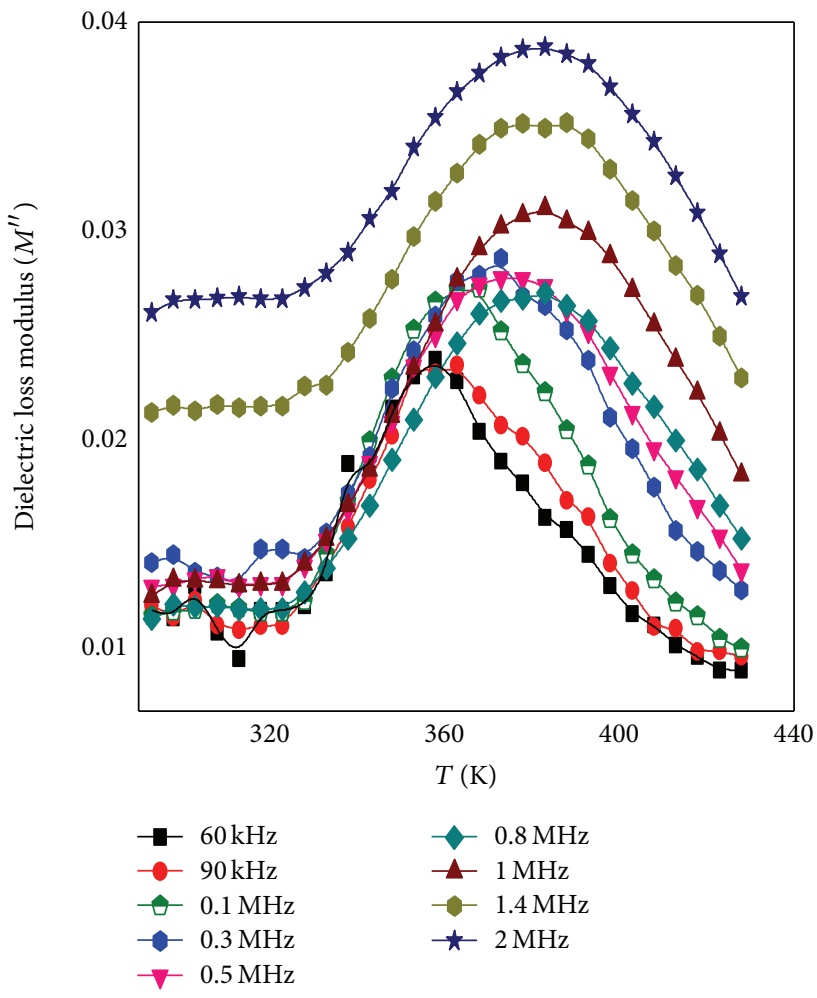

(b) 1 wt.\% NS

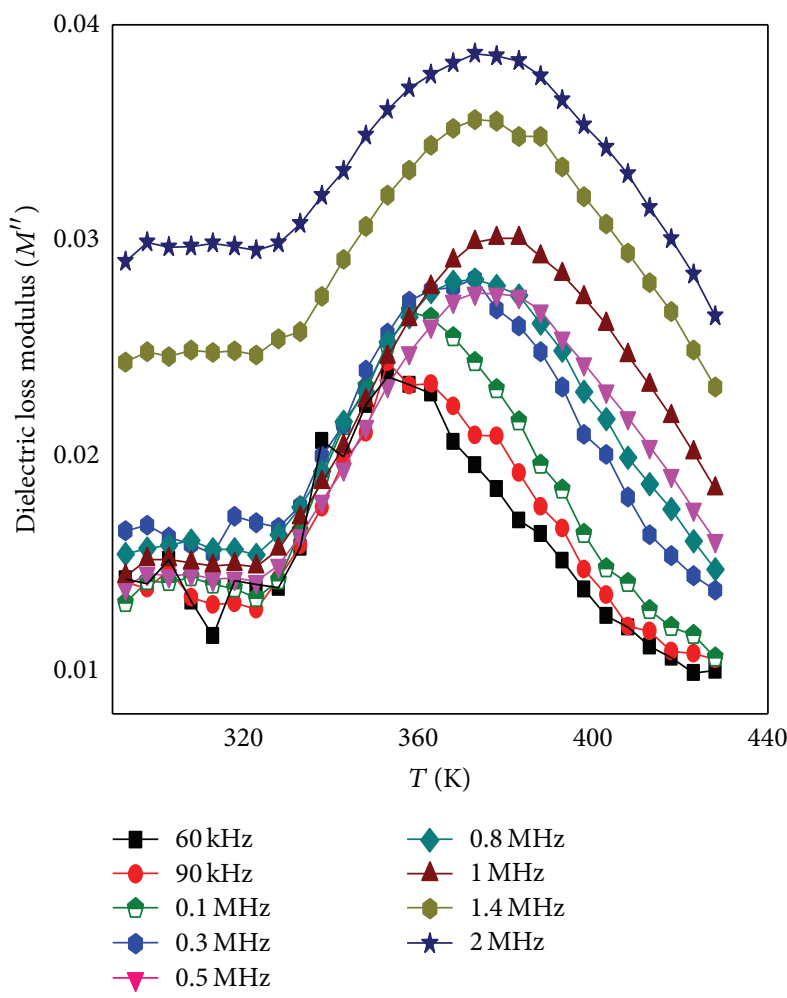

(d) $4 \mathrm{wt} . \% \mathrm{NS}$

FIGURE 11: The variation of dielectric modulus, $M^{\prime \prime}$, for pure PVC and $\mathrm{PVC}-\mathrm{SiO}_{2}$ nanocomposite films with temperature at different frequencies. 


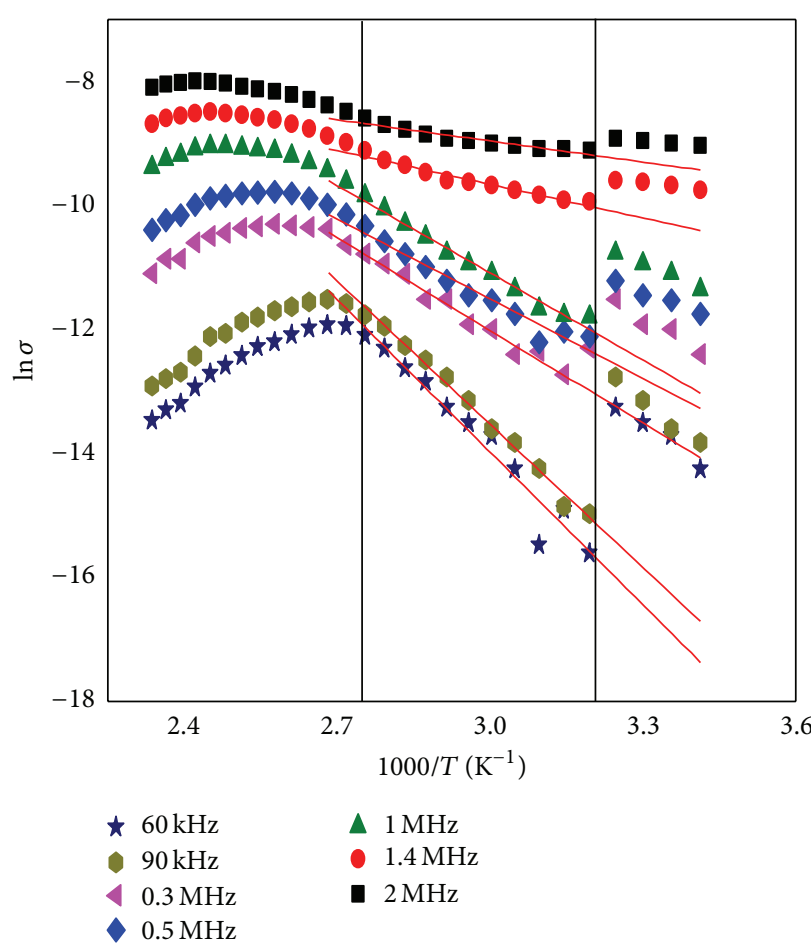

(a) Pure PVC

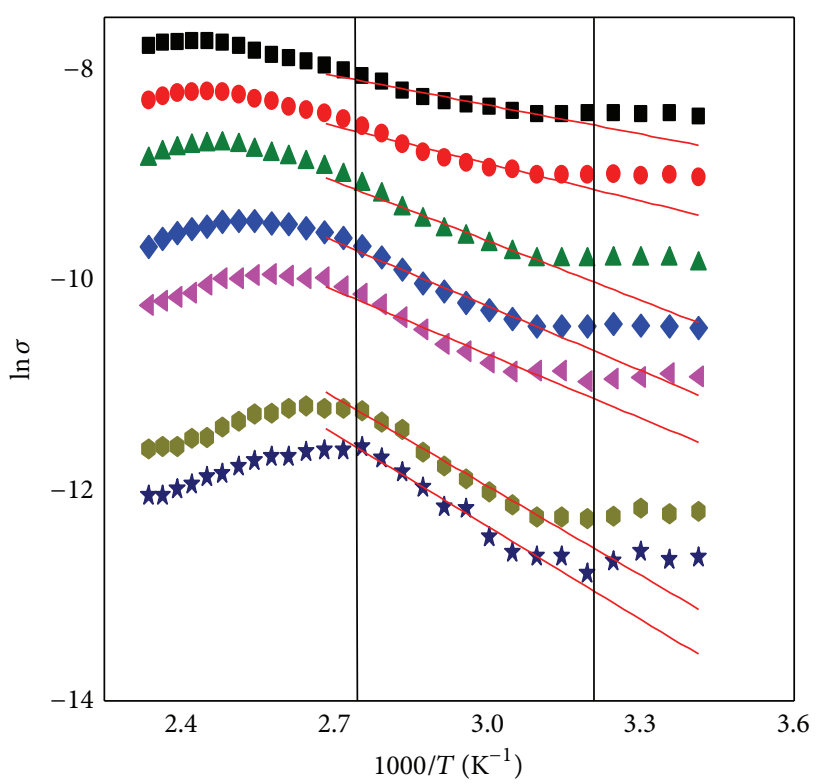

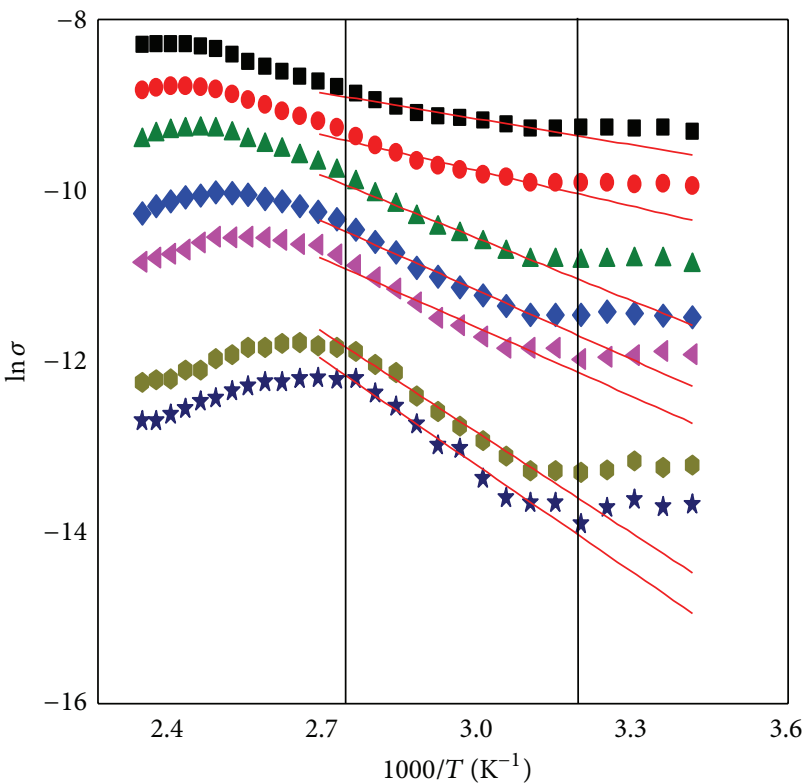
$\star 60 \mathrm{kHz}$
\ $1 \mathrm{MHz}$
- $90 \mathrm{kHz}$
- $1.4 \mathrm{MHz}$
$<0.3 \mathrm{MHz}$
- $2 \mathrm{MHz}$

$\downarrow 0.5 \mathrm{MHz}$

(b) $1 \mathrm{wt} . \% \mathrm{NS}$

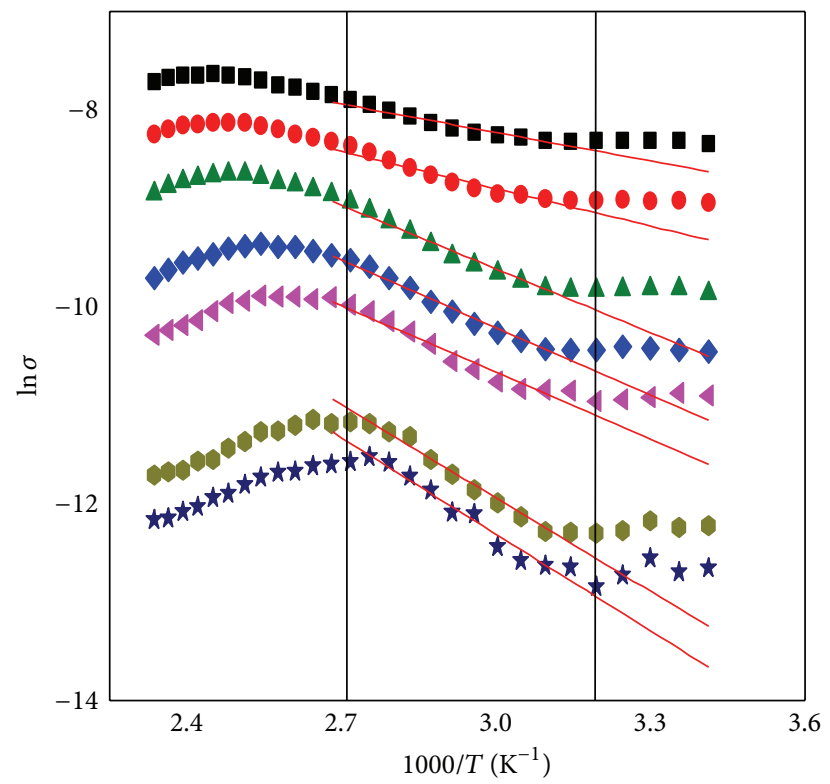
$\star 60 \mathrm{kHz}$
$\Delta 1 \mathrm{MHz}$
- $90 \mathrm{kHz}$
- $1.4 \mathrm{MHz}$
$40.3 \mathrm{MHz}$
- $2 \mathrm{MHz}$
$0.5 \mathrm{MHz}$

(d) 4 wt.\% NS

FIGURE 12: The variation of AC conductivity for pure PVC and PVC-SiO ${ }_{2}$ nanocomposite films with temperature at different frequencies. 
TABLE 2: Activation energies of pure $\mathrm{PVC}$ and $\mathrm{PVC} / \mathrm{SiO}_{2}$ nanocomposite films according to the Arrhenius relation within the temperature range of $300-370 \mathrm{~K}$.

\begin{tabular}{lcccc}
\hline \multirow{2}{*}{ Frequency } & \multicolumn{4}{c}{ Activation energy $E_{a}(\mathrm{eV})$} \\
& Pure PVC & $1 \% \mathrm{NS}$ & $2 \% \mathrm{NS}$ & $4 \% \mathrm{NS}$ \\
\hline $60 \mathrm{kHz}$ & 0.727 & 0.36 & 0.26 & 0.29 \\
$90 \mathrm{kHz}$ & 0.68 & 0.34 & 0.25 & 0.28 \\
$0.3 \mathrm{MHz}$ & 0.44 & 0.34 & 0.2 & 0.20 \\
$0.5 \mathrm{MHz}$ & 0.38 & 0.24 & 0.18 & 0.20 \\
$1 \mathrm{MHz}$ & 0.42 & 0.24 & 0.17 & 0.19 \\
$1.4 \mathrm{MHz}$ & 0.16 & 0.21 & 0.11 & 0.11 \\
$2 \mathrm{MHz}$ & 0.10 & 0.12 & 0.08 & 0.09 \\
\hline
\end{tabular}

be a hopping one [56]. Also, the variation of the conductance with temperature can be attributed to a combined effect of the change in the conductance with temperature and to the nature of the trap distribution inside the polymer networks.

\section{Conclusions}

Silica nanoparticles with an average particle size of $15 \mathrm{~nm}$ were successfully prepared and used for synthesis of $\mathrm{PVC} / \mathrm{SiO}_{2}$ nanocomposite films with 1,2 , and $4 \mathrm{wt} \%$ silica. It is found that the PVC-silica nanocomposite films were homogenous. The XRD analysis indicated that both the prepared silica nanoparticles and $\mathrm{PVC}-\mathrm{SiO}_{2}$ nanocomposite films have amorphous nature. The values of the optical band gap and Urbach energy were calculated using the optical method. The optical band gap was found to decrease with addition of nanosilica, while the Urbach energy $E_{U}$ values change inversely with optical band gap. The dispersion curves of the refractive index obey the single-oscillator model. The refractive index increased by increasing the silica nanoparticles content. These results may suggest the important applications of these nanocomposite films as optical devices.

The dielectric constant $\varepsilon^{\prime}$ increase with increasing temperatures and the $\alpha$-relaxation obtained around $T_{g}$ due to micro-Brownian motion were observed on the dielectric loss behavior. The temperature dependence behavior of the AC conductivity indicated that the conduction mechanism for all samples could be hopping. The activation energy $E_{a}$ for all samples was found to be decrease with addition of nanosilica; these results could be helpful for many applications of the nanocomposite films.

\section{Competing Interests}

The authors declare that they have no competing interests.

\section{References}

[1] S. Cho and W. Choi, "Solid-phase photocatalytic degradation of PVC- $\mathrm{TiO}_{2}$ polymer composites," Journal of Photochemistry and Photobiology A: Chemistry, vol. 143, no. 2-3, pp. 221-228, 2001.

[2] B. J. Ash, R. W. Siegel, and L. S. Schadler, "Glass-transition temperature behavior of alumina/PMMA nanocomposites,"
Journal of Polymer Science, Part B: Polymer Physics, vol. 42, no. 23, pp. 4371-4383, 2004.

[3] M. W. Pan, X. D. Shi, X. C. Li, H. Y. Hu, and L. C. Zhang, "Morphology and properties of PVC/clay nanocomposites via in situ emulsion polymerization," Journal of Applied Polymer Science, vol. 94, no. 1, pp. 277-286, 2004.

[4] I. S. Elashmawi, N. A. Hakeem, L. K. Marei, and F. F. Hanna, "Structure and performance of $\mathrm{ZnO} / \mathrm{PVC}$ nanocomposites," Physica B: Condensed Matter, vol. 405, no. 19, pp. 4163-4169, 2010.

[5] A. Olad and R. Nosrati, "Preparation and corrosion resistance of nanostructured PVC/ZnO-polyaniline hybrid coating," Progress in Organic Coatings, vol. 76, no. 1, pp. 113-118, 2013.

[6] W. E. Mahmoud and A. A. Al-Ghamdi, "The influence of $\mathrm{Cd}(\mathrm{ZnO})$ on the structure, optical and thermal stabilities of polyvinyl chloride nanocomposites," Polymer Composites, vol. 32, no. 7, pp. 1143-1147, 2011.

[7] F. Liu, H. Liu, X. Li et al., "Nano-TiO $@$ @Ag/PVC film with enhanced antibacterial activities and photocatalytic properties," Applied Surface Science, vol. 258, no. 10, pp. 4667-4671, 2012.

[8] A. Olad, S. Behboudi, and A. A. Entezami, "Effect of polyaniline as a surface modifier of $\mathrm{TiO}_{2}$ nanoparticles on the properties of polyvinyl chloride/ $\mathrm{TiO}_{2}$ nanocomposites," Chinese Journal of Polymer Science, vol. 31, no. 3, pp. 481-494, 2013.

[9] O. A. Al-Hartomy, F. Al-Salamy, A. A. Al-Ghamdi, M. Abdel Fatah, N. Dishovsky, and F. El-Tantawy, "Influence of graphite nanosheets on the structure and properties of PVC-based nanocomposites," Journal of Applied Polymer Science, vol. 120, no. 6, pp. 3628-3634, 2011.

[10] A. A. Al-Ghamdi, F. El-Tantawy, N. Abdel Aal, E. H. ElMossalamy, and W. E. Mahmoud, "Stability of new electrostatic discharge protection and electromagnetic wave shielding effectiveness from poly(vinyl chloride)/graphite/nickel nanoconducting composites," Polymer Degradation and Stability, vol. 94, no. 6, pp. 980-986, 2009.

[11] A. Chiappini, C. Armellini, A. Chiasera et al., "Design of photonic structures by sol-gel-derived silica nanospheres," Journal of Non-Crystalline Solids, vol. 353, no. 5-7, pp. 674-678, 2007.

[12] L. Pallavidino, D. S. Razo, F. Geobaldo et al., "Synthesis, characterization and modelling of silicon based opals," Journal of Non-Crystalline Solids, vol. 352, no. 9-20, pp. 1425-1429, 2006.

[13] C. T. Wang, C. L. Wu, I. C. Chen, and Y. H. Huang, "Humidity sensors based on silica nanoparticle aerogel thin films," Sensors and Actuators B: Chemical, vol. 107, no. 1, pp. 402-410, 2005.

[14] S. A. Grant, C. Weilbaecher, and D. Lichlyter, "Development of a protease biosensor utilizing silica nanobeads," Sensors and Actuators, B: Chemical, vol. 121, no. 2, pp. 482-489, 2007.

[15] H. Wang, Y. Bai, S. Liu, J. Wu, and C. P. Wong, "Combined effects of silica filler and its interface in epoxy resin," Acta Materialia, vol. 50, no. 17, pp. 4369-4377, 2002.

[16] H. Zhang, Z. Zhang, K. Friedrich, and C. Eger, "Property improvements of in situ epoxy nanocomposites with reduced interparticle distance at high nanosilica content," Acta Materialia, vol. 54, no. 7, pp. 1833-1842, 2006.

[17] S.-C. Kwon, T. Adachi, W. Araki, and A. Yamaji, "Thermoviscoelastic properties of silica particulate-reinforced epoxy composites: Considered in terms of the particle packing model," Acta Materialia, vol. 54, no. 12, pp. 3369-3374, 2006.

[18] P. Sharma, S. Brown, G. Walter, S. Santra, and B. Moudgil, "Nanoparticles for bioimaging," Advances in Colloid and Interface Science, vol. 123-126, pp. 471-485, 2006. 
[19] L. Jiang, W. Wang, D. Wu et al., "Preparation of silver quantum dots embedded water-soluble silica/PAAc hybrid nanoparticles and their bactericidal activity," Materials Chemistry and Physics, vol. 104, no. 2-3, pp. 230-234, 2007.

[20] C.-Y. Lai, C.-W. Wu, D. R. Radu, B. G. Trewyn, and V. S.Y. Lin, "Reversible binding and fluorescence energy transfer between surface-derivatized CdS nanoparticles and multifunctionalized fluorescent mesoporous silica nanospheres," Studies in Surface Science and Catalysis, vol. 170, pp. 1827-1835, 2007.

[21] G. Neri, G. Rizzo, C. Crisafulli et al., "Isomerization of $\alpha$-pinene oxide to campholenic aldehyde over Lewis acids supported on silica and titania nanoparticles," Applied Catalysis A: General, vol. 295, no. 2, pp. 116-125, 2005.

[22] J. L. Gole, C. Burda, Z. L. Wang, and M. White, "Unusual properties and reactivity at the nanoscale," Journal of Physics and Chemistry of Solids, vol. 66, no. 2-4, pp. 546-550, 2005.

[23] T. Jesionowski, K. Bula, J. Janiszewski, and J. Jurga, "The influence of filler modification on its aggregation and dispersion behaviour in silica/PBT composite," Composite Interfaces, vol. 10, no. 2-3, pp. 225-242, 2003.

[24] W. Brostow, T. Datashvili, and K. P. Hackenberg, "Synthesis and characterization of poly(methyl acrylate) $+\mathrm{SiO}_{2}$ hybrids," $E$ Polymers, vol. 8, no. 1, pp. 608-620, 2008.

[25] Y. Bolbukh, P. Kuzema, V. Tertykh, and I. Laguta, "Thermal degradation of polyethylene containing antioxidant and hydrophilic/hydrophobic silica," Journal of Thermal Analysis and Calorimetry, vol. 94, no. 3, pp. 727-736, 2008.

[26] T. H. Zhou, W. H. Ruan, Y. L. Mai, M. Z. Rong, and M. Q. Zhang, "Performance improvement of nano-silica/polypropylene composites through in-situ cross-linking approach," Composites Science and Technology, vol. 68, no. 14, pp. 2858-2863, 2008.

[27] W. H. Zhang, X. D. Fan, W. Tian, and W. W. Fan, "Polystyrene/nano- $\mathrm{SiO}_{2}$ composite microspheres fabricated by Pickering emulsion polymerization: Preparation, mechanisms and thermal properties," eXPRESS Polymer Letters, vol. 6, no. 7, pp. 532-542, 2012.

[28] Y. Bolbukh, V. Tertykh, P. Klonos, and P. Pissis, "DSC study of polyhydroxyethylmethacrylate filled with modified silicas," Journal of Thermal Analysis and Calorimetry, vol. 108, no. 3, pp. 1111-1119, 2012.

[29] M. Estevez, J. R. Rodriguez, S. Vargas, J. A. Guerra, W. Brostow, and H. E. H. Lobland, "Scratch and abrasion properties of polyurethane-based micro- and nano-hybrid obturation materials," Journal of Nanoscience and Nanotechnology, vol. 13, no. 6, pp. 4446-4455, 2013.

[30] S. Y. Yang, L. Liu, Z. X. Jia, W. W. Fu, D. M. Jia, and Y. F. Luo, "Study on the structure-properties relationship of natural rubber $/ \mathrm{SiO}_{2}$ composites modified by a novel multi-functional rubber agent," eXPRESS Polymer Letters, vol. 8, no. 6, pp. 425435, 2014.

[31] M. Maciejewska and M. Zaborski, "Effect of ionic liquids on the dispersion of zinc oxide and silica nanoparticles, vulcanisation behaviour and properties of NBR composites," Express Polymer Letters, vol. 8, no. 12, pp. 932-940, 2014.

[32] F. A. Al-Sagheer and Z. Ahmad, "PVC-silica hybrids: effect of sol-gel conditions on the morphology of silica particles and thermal mechanical properties of the hybrids," Journal of SolGel Science and Technology, vol. 61, no. 1, pp. 229-235, 2012.
[33] N. Gharehbash and A. Shakeri, "Modification of the surface of silica nanoparticles; studying its structure and thermal properties in order to strengthen it in preparing nanocomposites," Journal of American Science, vol. 9, no. 4, pp. 602-606, 2013.

[34] S. Maheswaran, B. Bhuvaneshwari, G. S. Palani, N. R. Iyer, and S. Kalaiselvam, "An overview on the influence of nano silica in concrete and a research initiative," Research Journal of Recent Sciences, vol. 2, pp. 17-24, 2013.

[35] W. E. Mahmoud, "Morphology and physical properties of poly(ethylene oxide) loaded graphene nanocomposites prepared by two different techniques," European Polymer Journal, vol. 47, no. 8, pp. 1534-1540, 2011.

[36] L. Hubert and J. V. Bonilla, Handbook of Plastics Analysis, Marcel Dekker, New York, NY, USA, 2003.

[37] M. Liu, L. Gan, L. Chen et al., "A novel liposome-encapsulated hemoglobin/silica nanoparticle as an oxygen carrier," International Journal of Pharmaceutics, vol. 427, no. 2, pp. 354-357, 2012.

[38] A. Fidalgo and L. M. Ilharco, "The defect structure of solgel-derived silica/polytetrahydrofuran hybrid films by FTIR," Journal of Non-Crystalline Solids, vol. 283, no. 1-3, pp. 144-154, 2001.

[39] M. Conradi, M. Zorko, I. Jerman, B. Orel, and I. Verpoest, "Mechanical properties of high density packed silica/poly(vinyl chloride) composites," Polymer Engineering and Science, vol. 53, no. 7, pp. 1448-1453, 2013.

[40] N. Reddeppa, A. K. Sharma, V. V. R. N. Rao, and W. Chen, "Preparation and characterization of pure and $\mathrm{KBr}$ doped polymer blend (PVC/PEO) electrolyte thin films," Microelectronic Engineering, vol. 112, pp. 57-62, 2013.

[41] W. E. Mahmoud, A. A. Al-Ghamdi, and F. Al-Agel, "Synthesis and optical properties of poly (vinyl acetate)/bismuth oxide nanorods," Polymers for Advanced Technologies, vol. 22, no. 12, pp. 2055-2061, 2011.

[42] R. Wen, L. Wang, X. Wang, G.-H. Yue, Y. Chen, and D.-L. Peng, "Influence of substrate temperature on mechanical, optical and electrical properties of $\mathrm{ZnO}$ :Al films," Journal of Alloys and Compounds, vol. 508, no. 2, pp. 370-374, 2010.

[43] F. Urbach, "The long-wavelength edge of photographic sensitivity and of the electronic absorption of solids," Physical Review, vol. 92, no. 5, p. 1324, 1953.

[44] I. S. Yahia, A. A. M. Farag, M. Cavas, and F. Yakuphanoglu, "Effects of stabilizer ratio on the optical constants and optical dispersion parameters of $\mathrm{ZnO}$ nano-fiber thin films," Superlattices and Microstructures, vol. 53, no. 1, pp. 63-75, 2013.

[45] S. H. Wemple and M. DiDomenico, "Behavior of the electronic dielectric constant in covalent and ionic materials," Physical Review B, vol. 3, no. 4, pp. 1338-1351, 1971.

[46] S. Mahrous, "Dielectric analysis of the $\alpha$-relaxation of PVC stabilized with cadmium laurate," Polymer International, vol. 40, no. 4, pp. 261-267, 1996.

[47] A. Belal, M. Amin, H. Hassan, A. Abd El-Mongy, B. Kamal, and $\mathrm{K}$. Ibrahim, "The role of $\mathrm{BaTiO}_{3}$ on the dielectric properties of polyvinyl chloride," Physica Status Solidi (A), vol. 144, no. 1, pp. K53-K57, 1994.

[48] T. A. Hanafy, "Dielectric relaxation and alternating-current conductivity of gadolinium-doped poly(vinyl alcohol)," Journal of Applied Polymer Science, vol. 108, no. 4, pp. 2540-2549, 2008.

[49] Ch. V. S. Reddy, X. Han, Q.-Y. Zhu, L.-Q. Mai, and W. Chen, "Dielectric spectroscopy studies on (PVP + PVA) polyblend film," Microelectronic Engineering, vol. 83, no. 2, pp. 281-285, 2006. 
[50] V. Rao, P. V. Ashokan, and M. H. Shridhar, "Studies of dielectric relaxation and a.c. conductivity in cellulose acetate hydrogen phthalate-poly(methyl methacrylate) blends," Materials Science and Engineering A, vol. 281, no. 1-2, pp. 213-220, 2000.

[51] C. T. Moynihan, L. P. Boesch, and N. L. Laberge, "Decay function for the electric field relaxation in vitreous ionic conductors," Physics and Chemistry of Glasses, vol. 14, no. 6, pp. 122-125, 1973.

[52] A. K. Jonscher, Dielectric Relaxation in Soilds, Chelsea Dielectric, London, UK, 1983.

[53] S. El-Sayed, T. Abel-Baset, A. A. Elfadl, and A. Hassen, "Effect of nanosilica on optical, electric modulus and AC conductivity of polyvinyl alcohol/polyaniline films," Physica B: Condensed Matter, vol. 464, pp. 17-27, 2015.

[54] M. D. Migahed, M. Ishra, T. Fahmy, and A. Barakat, "Electric modulus and AC conductivity studies in conducting PPy composite films at low temperature," Journal of Physics and Chemistry of Solids, vol. 65, no. 6, pp. 1121-1125, 2004.

[55] S. A. Saq'an, A. S. Ayesh, A. M. Zihlif, E. Martuscelli, and G. Ragosta, "Physical properties of polystyrene/alum composites," Polymer Testing, vol. 23, no. 7, pp. 739-745, 2004.

[56] S. Yu, P. Hing, and X. Hu, "Dielectric properties of polystyrenealuminum-nitride composites," Journal of Applied Physics, vol. 88, no. 1, pp. 398-404, 2000. 

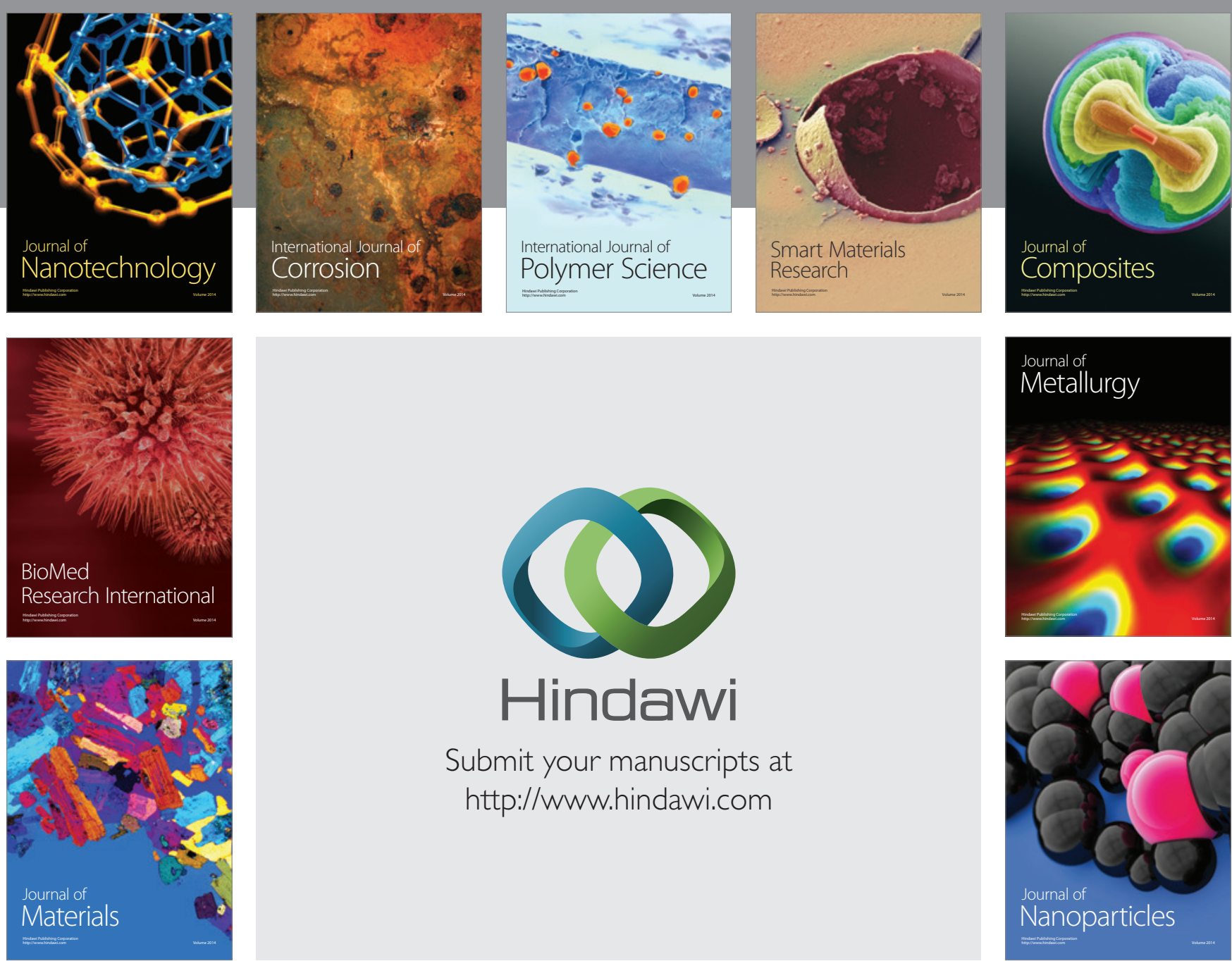

\section{Hindawi}

Submit your manuscripts at

http://www.hindawi.com

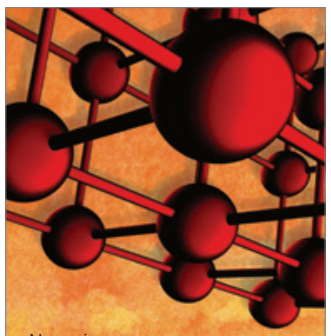

Materials Science and Engineering
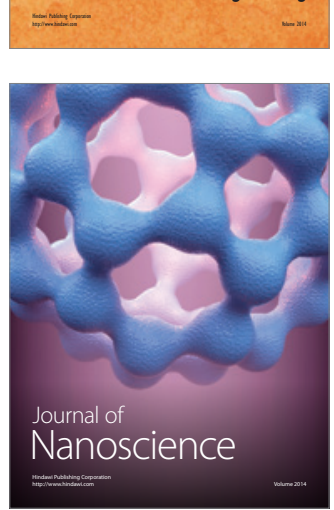
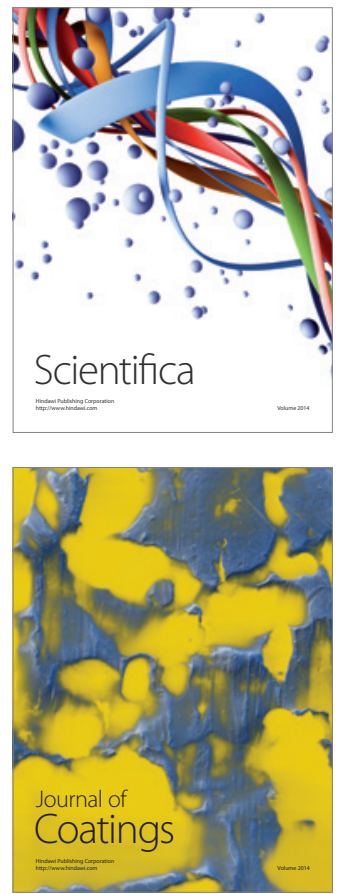
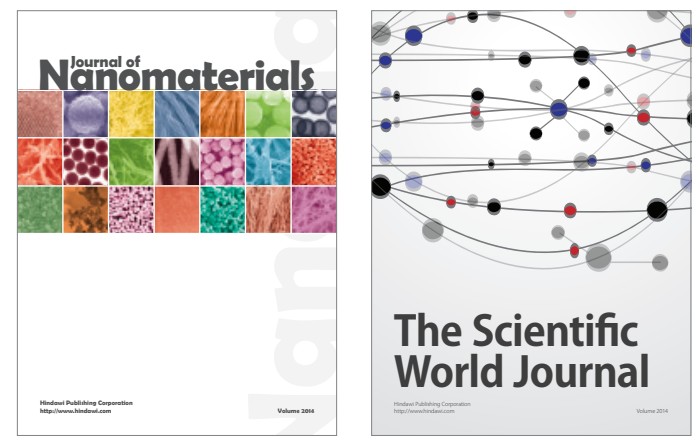

The Scientific World Journal
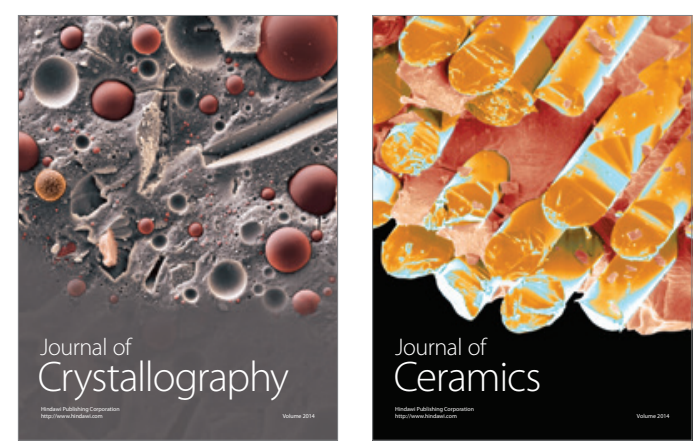
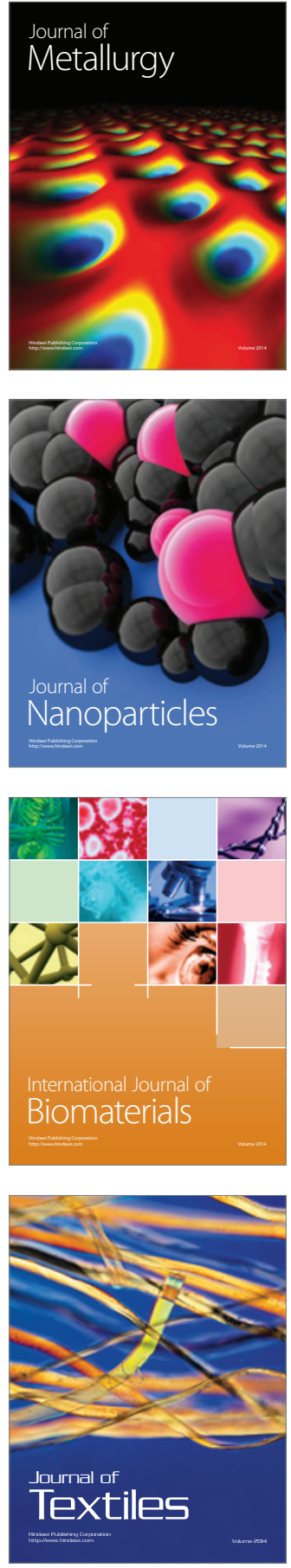